\title{
Stress Transfer Properties and Displacement Difference of GFRP Antifloating Anchor
}

\author{
Xiaoyu Bai $\mathbb{D},{ }^{1,2}$ Xueying Liu $\mathbb{D},{ }^{1}$ Mingyi Zhang $\mathbb{D},{ }^{1,2}$ Yonghong Wang, ${ }^{1,2}$ Zheng Kuang, \\ and Nan Yan ${ }^{1,2}$ \\ ${ }^{1}$ Department of Civil Engineering, Qingdao University of Technology, Qingdao, Shandong 266033, China \\ ${ }^{2}$ Cooperative Innovation Center of Engineering Construction and Safety in Shandong Blue Economic Zone, Qingdao, \\ Shandong 266033, China
}

Correspondence should be addressed to Mingyi Zhang; zhangmingyi@qut.edu.cn

Received 4 March 2020; Revised 22 June 2020; Accepted 3 July 2020; Published 28 July 2020

Academic Editor: Paolo Castaldo

Copyright (c) 2020 Xiaoyu Bai et al. This is an open access article distributed under the Creative Commons Attribution License, which permits unrestricted use, distribution, and reproduction in any medium, provided the original work is properly cited.

Glass fiber reinforced polymer (GFRP) antifloating anchors are widely used in reinforcing underground structures. Despite the outstanding application advances of GFRP anchors in the antifloating field, research on the mechanical transmission and deformation properties of the anchor rod and anchorage body is still scarce. This paper introduces pull-out experiments of GFRP antifloating anchors based on the FBG sensor strings technology. The experimental data demonstrates that the distribution curve of the axial stress shows a reversed-S shape, and the shear stress distribution presents the law of increasing first and then decreasing from the position of peak shear stress. The rod-anchorage body displacement difference curves of the anchors with an anchorage length that is closer to the critical anchorage length are smoother than those of the anchors with a larger length difference from the critical anchorage length. Finally, a simplified distribution model of the shear stress is applied for predicting the rod-anchorage body displacement difference, and the experimental data of the anchors with a rod slip failure is more applicable for this model than that of the anchors with a rod rupture failure.

\section{Introduction}

Floating issues of the buildings have been widely noticed in areas with high groundwater level or wet-dry circulation. As a type of antifloating approach, antifloating anchors are increasingly adopted for the anti-uplifting purpose [1]. However, it has been proven that conventional steel anchor deteriorates over time under the influence of detrimental environmental conditions with caustic ions [2-4], which severely weakens the strength of the underground structure and reduces the service life of antifloating anchors. In order to solve the durability problem of steel antifloating anchor, new advanced composite materials, known as fiber reinforced polymers (FRP), have been introduced as replacement for steel anchors, due to their high strength, good fatigue performance and damage tolerance, excellent resistance to environmental degradation, and low energy consumption during fabrication [5-8]. In general, there are three types of FRP materials in common use, i.e., carbon FRP (CFRP), aramid FRP (AFRP), and glass FRP (GFRP). With a lower elastic modulus, which is similar to that of concrete, than other two kinds of FRP rod [9], GFRP rods have better cooperativity with concrete, so the research of their mechanical properties is necessary. Recently, scholars have studied some mechanical aspects of GFRP rods such as durability assessment [10], bond strength [11, 12], loaddisplacement relationship [13, 14], and creep behavior [15].

In general, the antifloating anchor is a system which mainly consists of anchor rod and anchorage body (Figure 1). Kim performed pull-out tests and presented the stress distribution mode of steel anchor with several rods [16]. In the literature [1], Kou et al. conducted an in-site pull-out test of the GFRP anchors with a single rod and found similar stress distribution rules compared with the research of [16]. Their research works well revealed the stress properties of the rod-anchorage body interface. However, research on the 


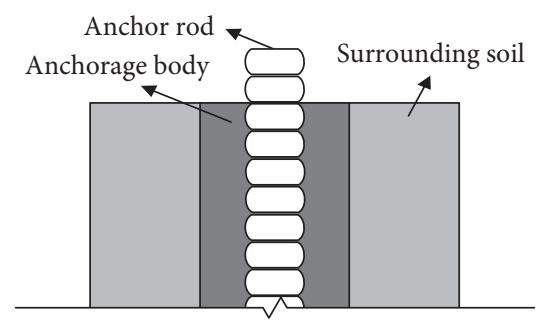

FIgURE 1: Component of the antifloating anchor system.

mechanical properties of the interface between anchorage body and surrounding soil is still rare, and a test database is required for better understanding the stress distribution rules at the anchorage body-surrounding soil interface. Another significant aspect is the stress transfer rules through the anchorage body, which is beneficial in providing a valuable reference to its design.

Apart from the stress distribution and transfer issue, the anchor displacement is a serious concern. Regarding this aspect, scholars mainly study the displacement of the anchor rod separately but ignore the displacement of the anchorage body [17-19]. Nevertheless, experimental results show that there is a displacement difference between the anchor rod and anchorage body due to the different material properties [20], which leads to a baseplate-anchor debonding effect and causes lower structure safety. Additionally, a much lower elastic modulus of GFRP rods than that of steel rods contributes to a more considerable rod deformation, and the anchorage body may show a more complex deformation mechanism. Hence, more attention should be paid to the displacement difference of GFRP anchor.

Recently, the use of Fiber Bragg grating (FBG) sensor technology has been extended to civil engineering field due to its advantages including high precision, good sensitivity, and strong anti-interference $[21,22]$. When monitoring the stress change properties, several FBG sensors will be connected to an FBG sensor string (Figure 2), and then armor and epoxy protective measures will be implemented to avoid string damage.

In this paper, pull-out experiments of GFRP antifloating anchors with a single rod are introduced. Three FBG sensor strings are arranged in different vertical interfaces to monitor the stress distribution, and based on the experimental data, the stress transfer rules in anchorage body are also discussed. Besides, the displacement difference between the anchor rod and the anchorage body is recorded and analyzed. A prediction model for the displacement difference, derived by the simplified distribution model for the shear stress, is presented. The research works provide the experimental and theoretical basis for the further application of GFRP antifloating anchor.

\section{Concept Explanation}

Before introducing the experimental work, some concepts need to be illuminated in order to avoid confusion and verbose sentences:

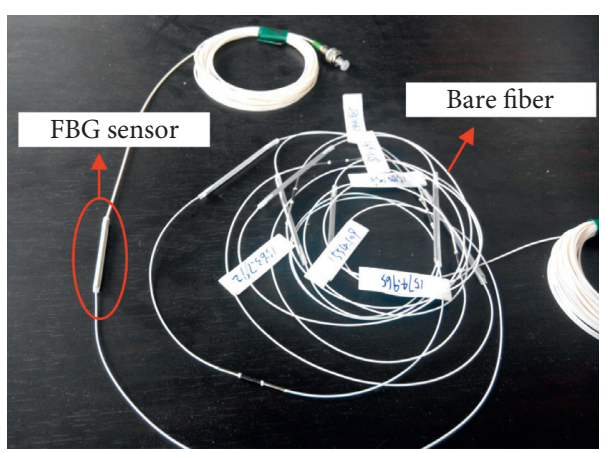

FIGURE 2: FBG sensor string.

(1) First interface: the interface between the anchor rod and the anchorage body

(2) Second interface: the interface between the anchorage body and surrounding soil

(3) Middle interface: the cylindrical interface at half the thickness of the anchorage body between the first and second interfaces

(4) Rod cross-section: the cross-section of the anchor rod, i.e., the cross-section inside the first interface

(5) Anchor cross-section: the cross-section of the whole anchor, i.e., the cross-section inside the second interface

(6) Middle cross-section: the cross-section inside the middle interface

(7) Critical anchorage length [23]: the most extended anchorage length which can effectively offset the pull-out load exerted on the anchor; the anchor is no longer stressed to exceed this length

\section{Monitoring Principle}

3.1. Arrangement of FBG Sensor Strings. In order to understand the stress variation at different interfaces, three vertical-prefabricated FBG sensor strings, which are connected with demodulator, are arranged at different interfaces parallelly. During the pull-out process, the experimental data are monitored and recorded by the demodulator.

The first interface, second interface, and middle interface are chosen to arrange the sensor strings, which are shown schematically in Figure 3.

As shown in Figure 3, the sensor strings 1, 2, and 3 are used in monitoring the axial stress of rod cross-section and shear stress of the first interface, the axial stress of middle cross-section and shear stress of the middle interface, and the axial stress of anchor cross-section and shear stress of the second interface, respectively.

Furthermore, the FBG sensors on sensor strings 2 and 3 are located at the edges of the cross-sections that they measure. However, the sensors on strings 1 are located in the center of the anchor rod because fixing FBG sensors at the edge of the rod's cross-section requires grooving on the rod's surface, and the groove would reduce the mechanical properties of the anchor rod. Although the positions are 


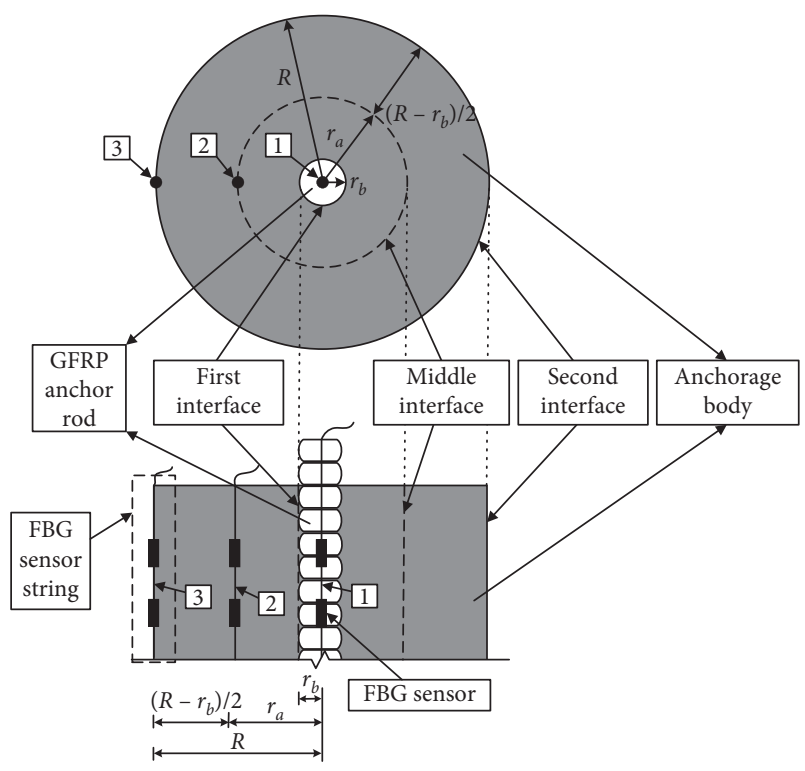

Figure 3: Arrangement of FBG sensor strings. Note. $r_{a}$ denotes the radius of the middle interface; $r_{b}$ denotes the radius of the first interface; $R$ denotes the radius of the second interface.

different, the data processing approach is the same for the three sensor strings.

The technology of implanting FBG sensor string in the center of the rod is to embed the sensor string in the center of the glass fiber bundle before fabricating the GFRP rod and casting the matrix materials (epoxy resin). After matrix hardening, the rod is manufactured and the sensor string is fixed in the center of the rod.

3.2. Approach of Data Processing. The FBG sensor will deform with the anchor under the pull-out load, which induces the variation of the sensor wavelength. In general, the wavelength is influenced by strain and temperature, which is calculated from

$$
\Delta \lambda=K_{\varepsilon} \Delta \varepsilon+K_{t} \Delta t
$$

where $\Delta \lambda$ is the wavelength variation of FBG sensor, $K_{\varepsilon}$ is the coefficient of strain sensitivity, $K_{t}$ is the coefficient of temperature sensitivity, $\Delta \varepsilon$ is the strain of the monitored part, and $\Delta t$ is the variation of temperature.

In this experiment, temperature compensation sensor strings were adopted for eliminating the effect of temperature variation. Hence, the wavelength variation of the FBG sensor is affected only by the sensor strain. The wavelength variation in equation (1) can be monitored by the demodulator so that the sensor strain can be obtained from equation (2). It is noticed that the sensor strain is equal to the strain of the anchor part connecting with the sensor:

$$
\Delta \varepsilon=\frac{\Delta \lambda}{K_{\varepsilon}} .
$$

Then, the load applied to an FBG sensor can be obtained from (3). Assuming that the distribution of the axial stress on the cross-section is uniform, the load calculated from (3) is equal to the axial stress on the cross-section that the FBG sensor monitors:

$$
\sigma_{s}=E \cdot \Delta \varepsilon,
$$

where $\sigma_{s}$ is the load applied to the FBG sensor and $E$ is the comprehensive elastic modulus of the monitored crosssection, which is calculated from

$$
E=\frac{\left(E_{r} \cdot S_{r}+E_{b} \cdot S_{b}\right)}{S}
$$

where $E_{r}$ and $E_{b}$ are the elastic modulus of anchor rod and anchorage body, respectively; $S_{r}$ is the cross-sectional area of the anchor rod; $S_{b}$ is the area of the anchorage body inside the cross-section monitored by the FBG sensor; and $S$ is the total area of the cross-section monitored by the FBG sensor, $S=S_{b}+S_{c}$.

The total axial force of the cross-section that the FBG sensor monitors is expressed as

$$
F=\sigma_{s} \cdot S,
$$

where $F$ is the total axial force of the cross-section.

As shown in Figure 4 (taking sensor string 1 as an example), the anchor portion between two cross-sections monitored by two adjacent FBG sensors ( $i$ and $i-1)$ on the same FBG sensor string is a cylinder. By the principle of static equilibrium, the axial force difference of two adjacent sensors is offset by the lateral shear stress of the cylinder mentioned above. Assuming that the shear stress is uniform, we obtain the following relation:

$$
F_{i}-F_{i-1}=2 \pi r \Delta L \cdot \tau_{i}
$$

where $F_{i}$ and $F_{i-1}$ are the axial force of the cross-section monitored by FBG sensor $i$ and $i-1$, respectively; $r$ is the radius of the monitored cross-section; $\Delta L$ is the distance between two FBG sensors; and $\tau_{i}$ is the average shear stress of the cylinder surface between sensor $i$ and $i-1$. It is noticed that half the distance between the two sensors $(\Delta L / 2)$ is considered to be the action point of the average shear stress when drawing the shear stress distribution curve.

\section{Experimental Program}

4.1. Experimental Site Details. According to the survey report of the experiment site, the underground rock layers are moderately decomposed granite (MDG) and micro-weathered granite in sequence. The main structure of MDG is the coarse grain structure and rock block structure. Its mineral composition is feldspar and quartz, and contains more biotite and hornblende dark mineral. The rock stratum joint fissure develops, the weathered fissure has a small amount of dark mineral, and its hammer sound is crisp, not easy to break, and the thickness is $1.60-9.30 \mathrm{~m}$. All test anchor whole anchorage length of the specimens are embedded in this soil layer (MDG). The depth of underground water is $0.80 \sim 4.20 \mathrm{~m}$ and its amplitude of annual variation is $1.00 \sim 1.50 \mathrm{~m}$. Other important mechanical parameters are summarized in Table 1.

4.2. GFRP Rod Details. The performance of a total of ten antifloating anchor specimens containing GFRP rods with three kinds of dimensions was investigated. These rods consist of glass fiber and epoxy resin with the respective 


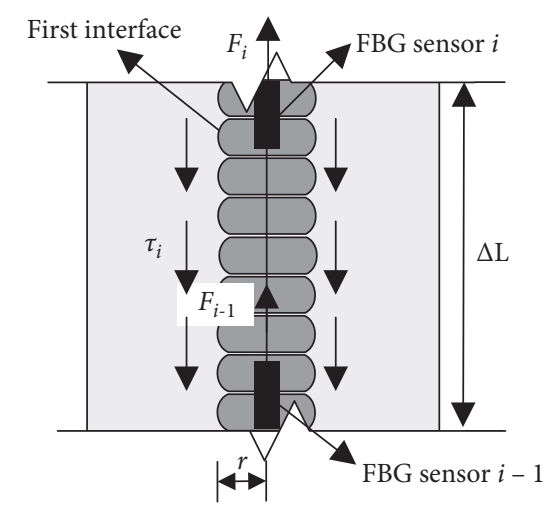

FIgURE 4: Stress condition between two adjacent FBG sensors.

TABLE 1: Mechanical parameters of MDG soil layer.

\begin{tabular}{lcccc}
\hline Unit weight $\left(\mathrm{kN} / \mathrm{m}^{3}\right)$ & Internal friction angle $\left(^{\circ}\right)$ & Cohesive force $(\mathrm{MPa})$ & Elastic modulus $(\mathrm{GPa})$ & $\begin{array}{c}\text { Poisson's ratio } \\
\text { Uniaxial compressive } \\
\text { strength }(\mathrm{MPa})\end{array}$ \\
\hline 24.5 & 38.0 & 51.0 & 5.0 & 0.3 \\
\hline
\end{tabular}

volume fractions of $25 \%$ and $75 \%$. Besides, the density, tensile strength, shear strength, and elastic modulus of these rods are $2.1 \mathrm{~g} / \mathrm{cm}^{3}, 675 \mathrm{MPa}, 150 \mathrm{MPa}$, and $51 \mathrm{GPa}$, respectively.

The nomenclature for each of the anchor specimens is in the form of the rod's material, their respective dimensions (designated as $x$ and $y$ ), and their sequence number (designated as $z$ ), i.e., G- $x-y-z$. The meaning denoted by each symbol is explained as follows:

$G$ represents the material of anchor rod, i.e., GFRP $x$ represents the diameter of the anchor rod (unit: $\mathrm{mm}$ ) $y$ represents the length of the rod (unit: $\mathrm{m}$ ) $z$ represents the sequence number

For example, G-28-6.5-1 means the first anchor specimen containing GFRP rod with a $28 \mathrm{~mm}$ diameter and $6.5 \mathrm{~m}$ length.

The quantities of the specimens G-28-6.5, G-28-4.5, G-32-4.5 are four, four, and two, respectively. Also, there are 3 anchors which installed FBG sensor strings, i.e., G-28-6.51, G-28-6.5-2, and G-28-4.5-1.

4.3. FBG Sensor String Arrangement and Installation. On a sensor string, the arrangement of FBG sensors adopted a method of more above and less below, so the main force range of the anchor is in the upper part of the anchorage section [24]. The nearest four FBG sensors from the ground surface were $0.3 \mathrm{~m}$ apart, and from the fifth FBG sensor, the distance between two adjacent FBG sensors was $0.6 \mathrm{~m}$, until the remainder of the anchorage length was less than $0.6 \mathrm{~m}$. The distance between two adjacent temperature sensors on a temperature compensation sensor string was $1.0 \mathrm{~m}$. In according to part 3.1, the arrangement of sensor strings is shown in Figure 5 (take the anchor G-28-6.5-1 as an example).

As for the aspect of the installation and fixing of the sensor strings, the technology of implanting FBG sensor string in the center of the rod mentioned in part 3.1 was adopted for fixing string 1 shown in Figure 3. However, sensor strings 2 and 3 shown in Figure 3 applied an approach of bidirectional fixation, which is shown schematically in Figure 6.

As shown in Figure 6, the radius of the centralizers is equal to the radius of the anchor cross-section, and the sensor strings are bound on the axial fixed wires. Figure 7 shows the anchor rods after sensor installation.

\subsection{Construction of GFRP Antifloating Anchors}

4.4.1. Drilling Holes. In this process, the distance of the anchor holes was $3.0 \mathrm{~m}$, in order to avoid the anchor group effect [25]. The depth of the holes exceeded the rod length by $0.5 \mathrm{~m}$; i.e., the depths of three types of anchor holes were $7 \mathrm{~m}$, $5 \mathrm{~m}$, and $5 \mathrm{~m}$, respectively. The diameter of these holes was $120 \mathrm{~mm}$.

4.4.2. Putting Anchor Rod in the Hole. The drilling machinery was applied to ensure that the rod was vertical and the FBG sensors were intact.

4.4.3. Grouting and Mortar Curing. After the anchor putting process, the commercial cement mortar was poured into the anchor hole. Then the curing process was conducted for 28 days. In addition, according to the requirements of the Chinese national standard technical code for ground treatment of buildings (JGJ79-2012), three cubes with the dimension of $150 \mathrm{~mm}$ were cast and cured in the same manner to monitor the compressive strength of concrete. 


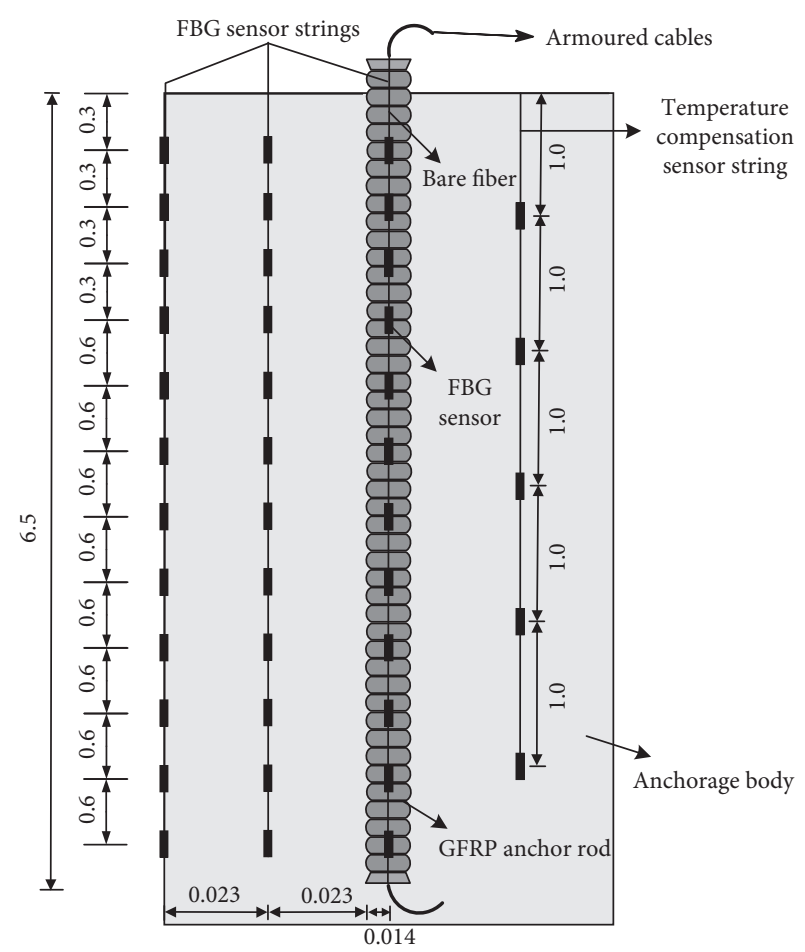

FIgURE 5: Arrangement of sensor strings (unit: $\mathrm{m}$ ).

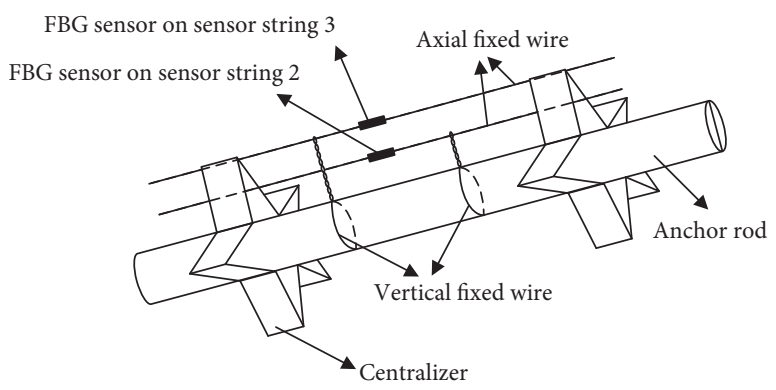

FIGURE 6: Fixation approach of sensor strings.

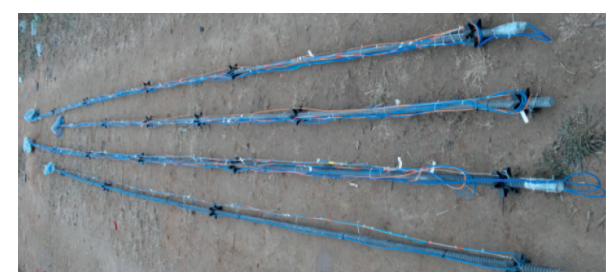

FIgURE 7: Anchor rods after sensor installation.

The average compressive strength of the cubes is $34.1 \mathrm{MPa}$, which met the experimental requirements. After the curing, the elastic modulus of the cement mortar, i.e., the elastic modulus of the anchorage body, could be calculated as in the literature [26]:

$$
E_{b}=1057 \cdot f_{b}^{0.84}
$$

where $f_{b}$ is the compressive strength of the cement mortar.

The elastic modulus of the cement mortar in this experiment is $20.492 \mathrm{GPa}$ after calculation.

4.5. Experiment Setup and Instrumentation. After the mortar curing process, the pull-out experiment was conducted. The loading device is shown in Figure 8.

The approach of monotonous step-by-step loading was adopted during the loading process, the load value per stage was $40 \mathrm{kN}$, and the loading speed was $0.2 \mathrm{kN} / \mathrm{s}$. There was a 10-minute interval between the end moment of a loading stage and the start moment of the next loading stage. In addition, the value of the displacement indicators after each loading stage was recorded.

The failure of the experimental anchor could be identified as recommended in the Chinese national standard code for design of building foundation (GB50007-2011). The value of the ultimate bearing capacity of the anchors was the load of the stage before the anchor failure happened, and the displacement corresponding to the ultimate bearing capacity was the maximum displacement of the anchor rod or anchorage body.

\section{Experimental Results and Discussion}

5.1. Anchor Failure Mode. In accordance with the test phenomena, there were two kinds of failure modes of the GFRP anchors. The first one was the rod slip failure; i.e., a shear slip failure occurred at the first interface, and the rod was drawn out but the anchorage body was not, as shown in Figure 9(a). In the second one, the anchor rod was ruptured, as shown in Figure 9(b). In addition, the failure load, the maximum displacement of the anchor rod and anchorage body, and the failure mode of each anchor are summarized in Table 2.

5.2. Failure Load. The failure loads of the experimental anchors are summarized in Figure 10, in order to clearly show their variation rules.

Combining the anchor failure loads in Figure 10 and the failure modes in Table 2, it is revealed that the failure load of the experimental anchors which exhibit a rod rupture failure is a little higher than that of the anchors which exhibit a rod slip failure, under the same rod dimension condition. The reason for this rule can be explained as below.

The cement mortar is inevitably uneven during the grouting and curing process, which leads to uneven bonding of the anchor rod and anchorage body at the first interface. When the total bonding strength of the first interface is lower than the material tensile strength, a rod slip failure will happen. On the contrary, if the total bonding strength of the first interface is higher than the material tensile strength, a rod rupture failure will happen. Because the tensile strength of the same material is specific, the failure load of the experimental anchors with a rod rupture failure is higher than that of the anchors with a rod slip failure. 


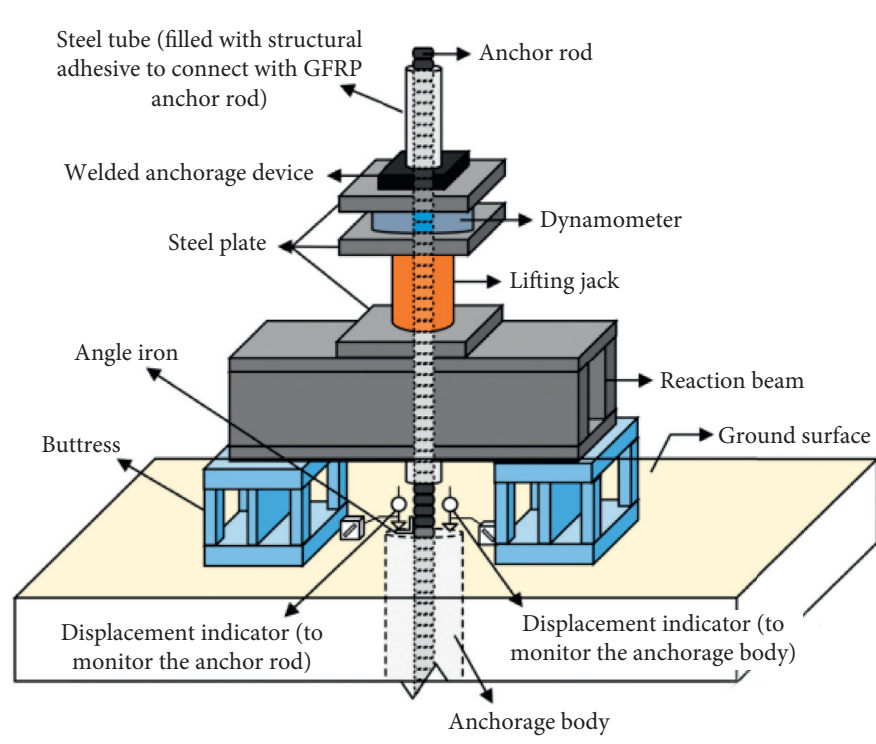

(a)

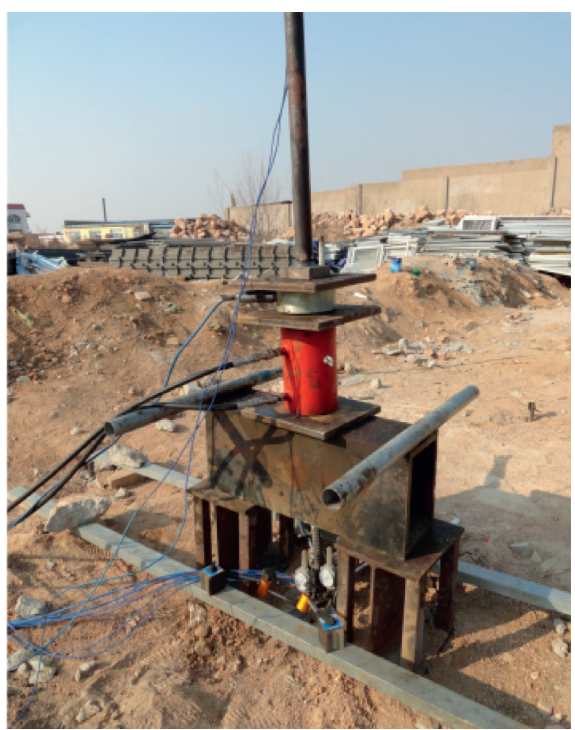

(b)

FIGURE 8: Loading device: (a) schematic diagram and (b) realistic photo.

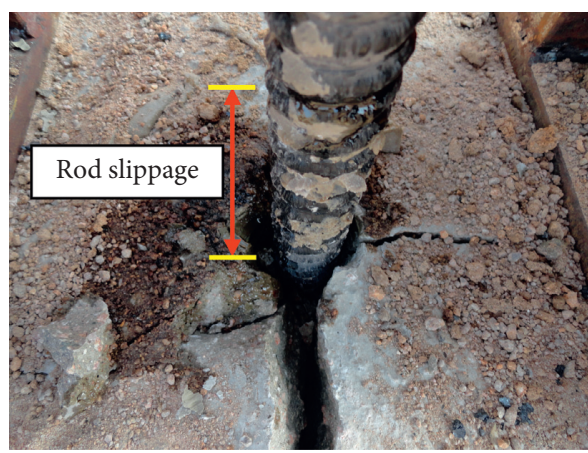

(a)

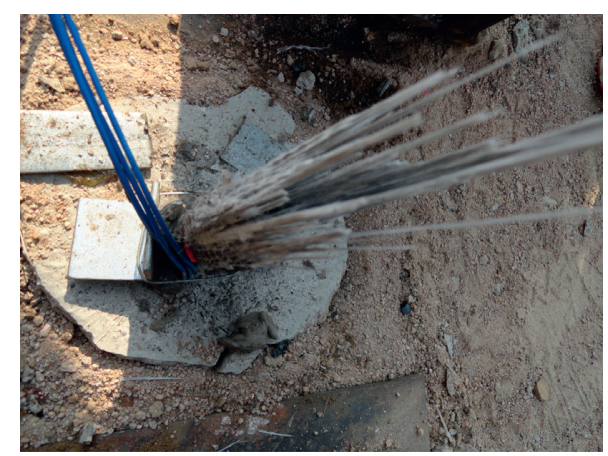

(b)

Figure 9: Photos of the failure modes of the experimental anchors: (a) rod slip failure and (b) rupture of the anchor rod.

TABLE 2: Experimental results of the GFRP antifloating anchors.

\begin{tabular}{|c|c|c|c|c|}
\hline Anchor no. & $\begin{array}{c}\text { Failure load } \\
(\mathrm{kN})\end{array}$ & $\begin{array}{l}\text { Maximum displacement of anchor rod } \\
(\mathrm{mm})\end{array}$ & $\begin{array}{l}\text { Maximum displacement of anchorage body } \\
(\mathrm{mm})\end{array}$ & $\begin{array}{c}\text { Failure } \\
\text { mode }\end{array}$ \\
\hline G-28-6.5-1 & 395 & 14.02 & 12.63 & Rod rupture \\
\hline G-28-6.5-2 & 378 & 16.47 & 12.64 & Rod slip \\
\hline G-28-6.5-3 & 412 & 14.89 & 12.25 & Rod rupture \\
\hline G-28-6.5-4 & 387 & 18.26 & 13.27 & Rod slip \\
\hline G-28-4.5-1 & 407 & 15.86 & 12.035 & Rod rupture \\
\hline G-28-4.5-2 & 381 & 17.03 & 12.67 & Rod slip \\
\hline G-28-4.5-3 & 394 & 15.21 & 11.47 & Rod rupture \\
\hline $\mathrm{G}-28-4.5-4$ & 375 & 16.74 & 11.35 & Rod slip \\
\hline G-32-4.5-1 & 467 & 15.87 & 12.31 & Rod slip \\
\hline G-32-4.5-2 & 453 & 17.69 & 12.64 & Rod slip \\
\hline
\end{tabular}

The average failure load for the G-28-6.5 anchors is $393 \mathrm{kN}$, which is similar to that of the G-28-4.5 anchors $(389.25 \mathrm{kN})$. The anchorage length increases by $2 \mathrm{~m}$, but the failure load is not promoted, which implies that the critical anchorage length of the GFRP antifloating anchor under this condition is equal to or shorter than $4.5 \mathrm{~m}$. 


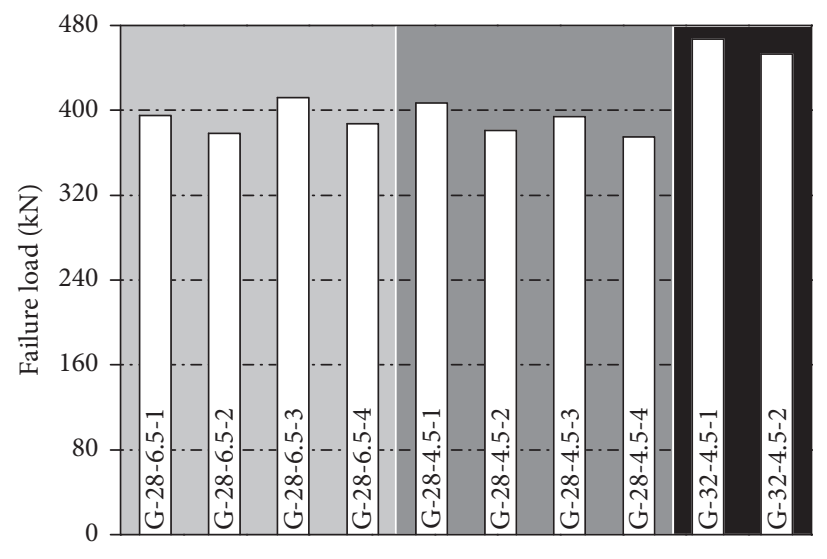

FIgURE 10: Summary of the anchor failure load.

The average failure load of the G-32-4.5 anchors is $460 \mathrm{kN}$, which is $21.69 \%$ higher than that of the G-28-4.5 anchors, i.e., $378 \mathrm{kN}$, indicating that the increase of the rod diameter is beneficial to improve the bearing capacity of GFRP anchors. The following equation could explain this rule:

$$
P=\pi d_{r} \cdot \int_{0}^{L_{a}} \tau(x) \mathrm{d} x,
$$

where $P$ is the pull-out load, $d_{r}$ is the diameter of the anchor rod, $L_{a}$ is the anchorage length, and $\tau(x)$ is the shear stress of the first interface at a depth of $x$.

It is well known that the shear strength, i.e., the maximal shear stress, for two certain kinds of materials is a constant value, and the shear strength corresponds to failure load. Hence, as revealed in (8), under the condition of the same anchorage length and shear strength, the failure load of the anchor will be promoted with the increase of the anchor rod diameter. However, it should be noticed that the increased percentage of the failure load is not equal to that of the rod diameter by the experimental results, which is not coincident with what (8) shows and needs future research.

5.3. Axial Stress Distribution. Figures 11-13 show the variation of measured axial stress of rod cross-section, middle cross-section, and anchor cross-section at different depths, respectively.

From Figure 11, it can be noticed that the curve of the axial stress of the rod cross-section presents a reversed-S shape. The axial stress decreases from the head to the bottom of the anchor hole, and a large reduction appears in the range of $0.3 \sim 1.2 \mathrm{~m}$ depth, which is consistent with Kim's research result [16]. With the improvement of the pull-out load, the axial stress at the same depth also increases.

Also, it can be inferred that the critical anchorage length of GFRP anchor with a $28 \mathrm{~mm}$ diameter is about $3.3 \mathrm{~m}$ under this experimental condition, since the axial stress almost disappears as the anchorage depth exceeds $3.3 \mathrm{~m}$. This conclusion is consistent with the conclusion of the critical anchorage length in Section 5.2.
As shown in Figures 12 and 13, similar to anchor crosssection, the axial stress curves of middle and anchor crosssection present a law that the stress decreases from the head to the bottom of the anchor hole. It is also noticed, however, that the farther the distance from the center, the smaller the axial stress, which indicates an axial stress reduction through the anchorage body.

5.4. Shear Stress Distribution. Figures 14-16 show the variation of measured shear stress of the first, middle, and second interface at different depths, respectively.

As depicted in Figure 14, the shear stress of the first interface, which disappears near the $3.3 \mathrm{~m}$ depth, presents a law of increasing first and then decreasing. The peak shear stress is $4.0-4.5 \mathrm{MPa}$ and appears at the $1.05 \mathrm{~m}$ depth. According to Figures 15 and 16, the shear stress curves of the middle and second interface show a similar pattern to that of the first interface, but the appearing location (i.e., $0.45 \mathrm{~m}$ ) of the peak value is shallower than that of the first interface. Other laws of shear stress will be introduced in the next section.

Failure is most likely to occur at the maximum position of the shear stress. Hence, suitable strengthening at this position is beneficial to improve the anchorage capacity of anchors.

5.5. Shear Stress Transfer Laws in the Anchorage Body. On the basis of the shear stress distribution curves shown in Figures 14-16, the locations and values of the peak shear stress of three vertical interfaces are depicted in Figures 17 and 18 , respectively.

As shown in Figure 17, the location of the peak shear stress point of different vertical interfaces within the anchorage body moves up from the center to the sides of the anchor, and the line connecting the peak shear stress points is oblique-upward.

Furthermore, as shown in Figure 18, the peak values of the shear stress decrease from the first interface to the second interface gradually. Between the first interface and the middle interface, the shear stress experiences a rapid drop 


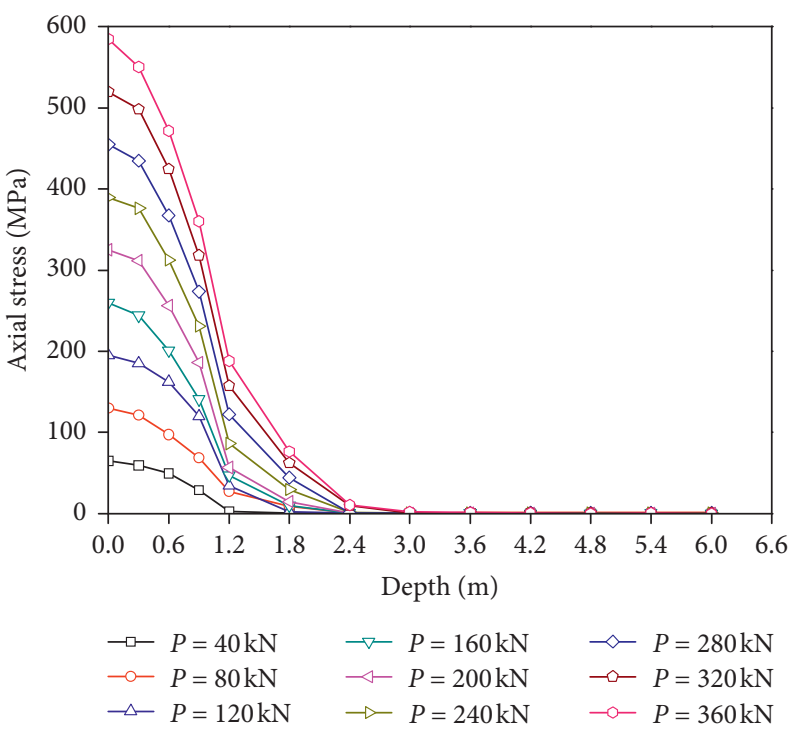

(a)

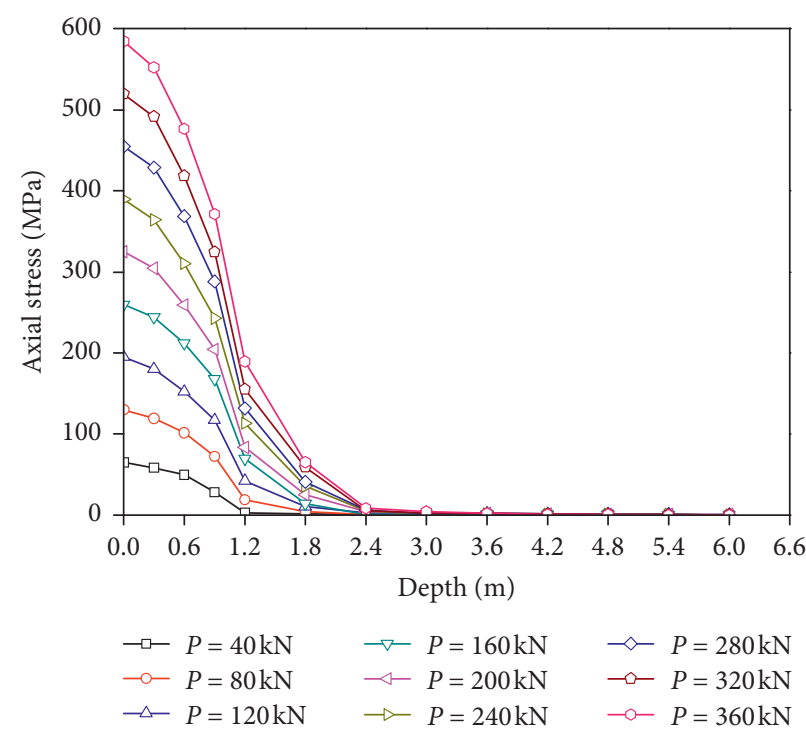

(b)

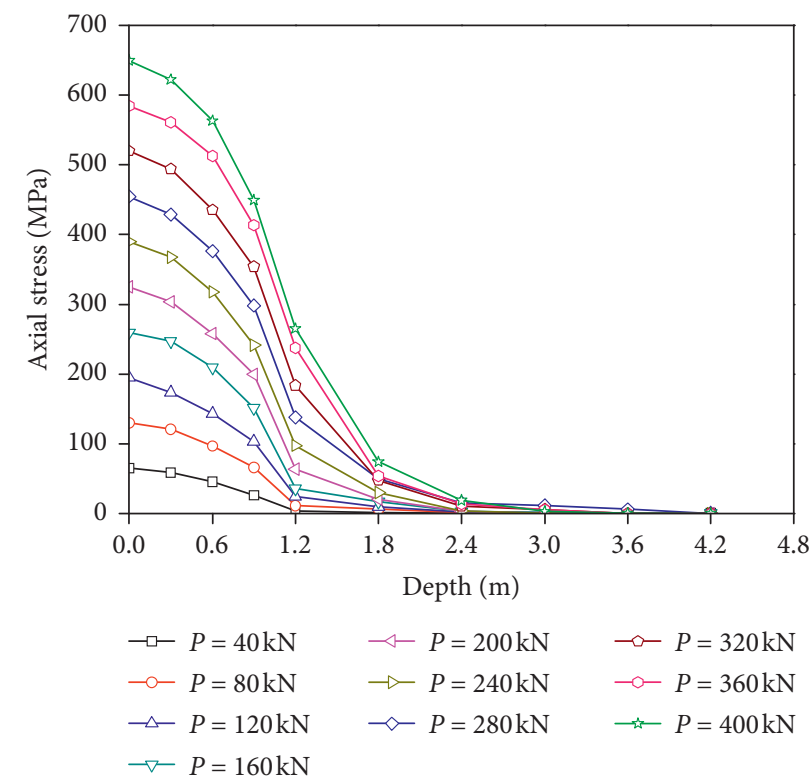

(c)

Figure 11: Axial stress of rod cross-section at different depths: (a) G-28-6.5-1, (b) G-28-6.5-2, and (c) G-28-4.5-1.

(more than 90\% reduction rate). Therefore, the reduction rate between the middle interface and the second interface is tiny.

5.6. Load-Displacement Difference Curve between the Anchor Rod and Anchorage Body. The load-displacement difference curves of experimental anchors are summarized in Figure 19. It should be noticed that there are two kinds of failure modes for each dimension of the anchors with a $28 \mathrm{~mm}$ rod diameter and one kind of failure mode for the anchors with a $32 \mathrm{~mm}$ rod diameter, as shown in Table 2. Hence, in order to reveal the laws of load-displacement difference curve more concisely, the average value of the displacement difference between anchor rod and anchorage body with the same rod dimension and failure mode is chosen for the anchors with a
$28 \mathrm{~mm}$ rod diameter, but the anchors with a $32 \mathrm{~mm}$ rod diameter apply the experimental data directly.

Based on the curves shown in Figure 19, the change laws of the load-displacement difference curves under single variate are analyzed as follows:

(1) Different failure modes: the load-displacement difference curves of the anchors with different failure modes are shown in Figure 20.

According to Figure 20, before the load reaches $160 \mathrm{kN}$, the displacement differences of the anchors with the same dimension show a similar improvement. However, after $160 \mathrm{kN}$ load stage, the increment speed of the anchors with slip failure is greater than that of the anchors with rupture failure, 


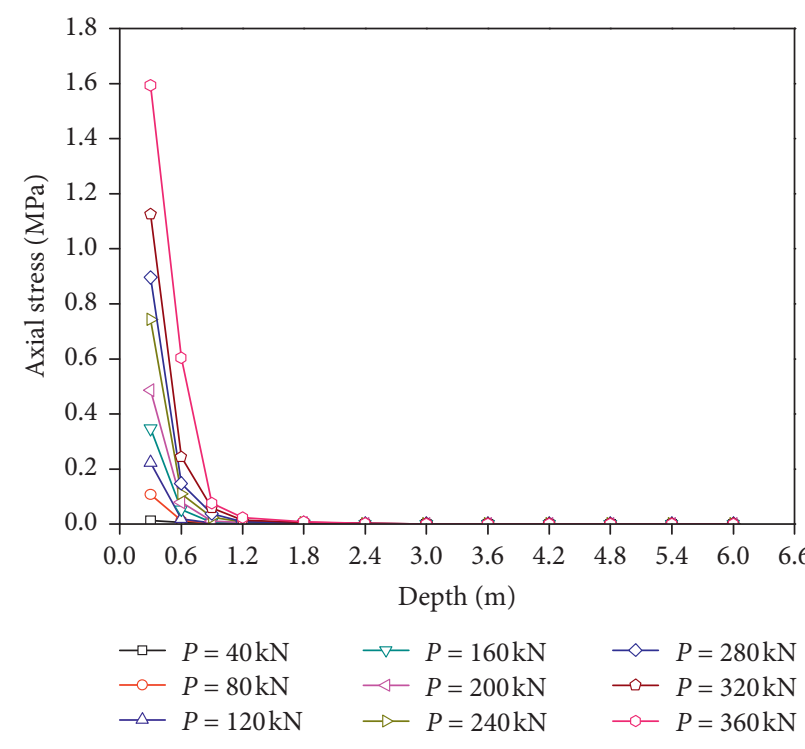

(a)

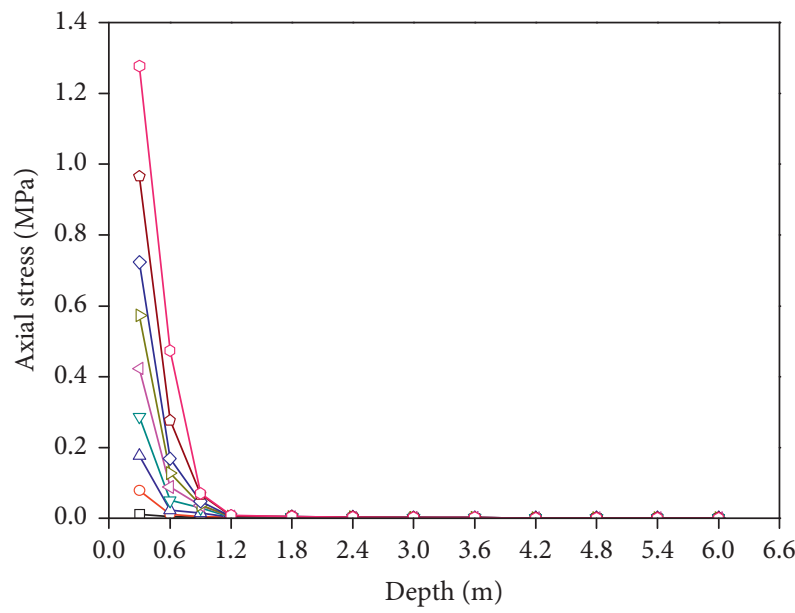

$$
\begin{array}{lll}
\multimap-P=40 \mathrm{kN} & \rightarrow P P=160 \mathrm{kN} & \neg P P=280 \mathrm{kN} \\
\multimap-P=80 \mathrm{kN} & \multimap-P=200 \mathrm{kN} & \multimap-P=320 \mathrm{kN} \\
\neg-P=120 \mathrm{kN} & \rightarrow-P=240 \mathrm{kN} & \multimap P=360 \mathrm{kN}
\end{array}
$$

(b)

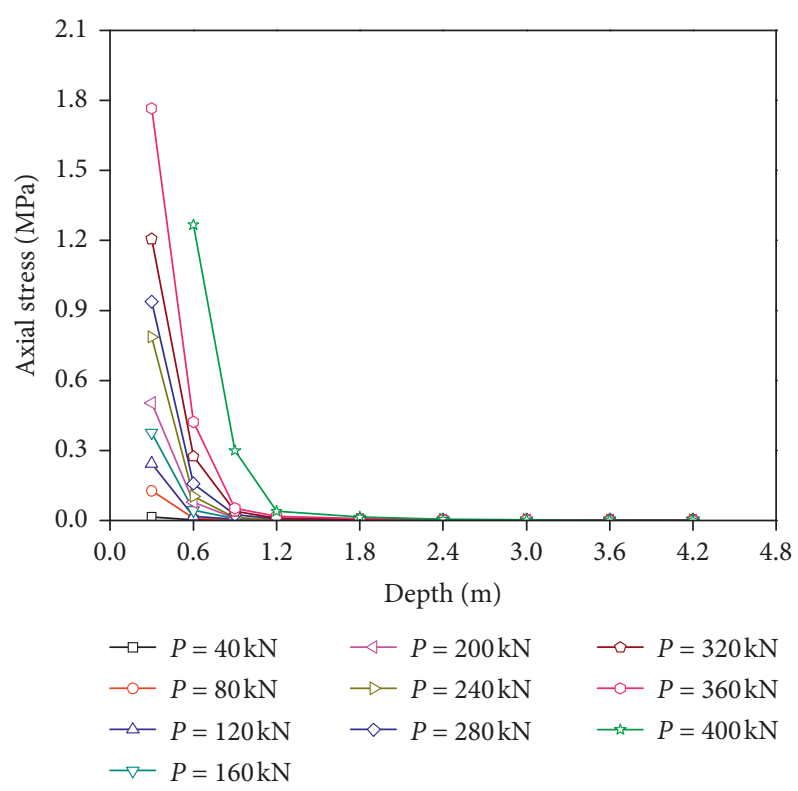

(c)

Figure 12: Axial stress of middle cross-section at different depths: (a) G-28-6.5-1, (b) G-28-6.5-2, and (c) G-28-4.5-1.

indicating a better synergetic load-carrying capacity of the anchor with rupture failure than the anchor with slip failure.

The reason for the above phenomenon is that the bonding force at the first interface of the anchor with slip failure is consumed at a higher speed, which leads to earlier damage to the first interface. Then a more massive displacement of the rod occurs.

(2) Different anchorage lengths: the load-displacement difference curves of the anchors with different anchorage lengths are shown in Figure 21.

As shown in Figure 21, the displacement difference curves of the anchors with a $4.5 \mathrm{~m}$ anchorage length (i.e., G-28-4.5) present a more stable upward trend than that of the anchors with a $6.5 \mathrm{~m}$ anchorage length (i.e., G-28-6.5). Before $280 \mathrm{kN}, \mathrm{G}-28-6.5$ anchors present a stable upward trend like G-28-4.5 anchors. At a particular stage after $280 \mathrm{kN}$, however, a sudden decline occurs on the curves of G-28-6.5 anchors and then an increase occurs again.

(3) Different rod diameters: the load-displacement difference curves of the anchors with different rod diameters are shown in Figure 22.

As shown in Figure 22, the values of the displacement difference of G-32-4.5 anchors are lower than those of the G-32-6.5 anchors, indicating that 


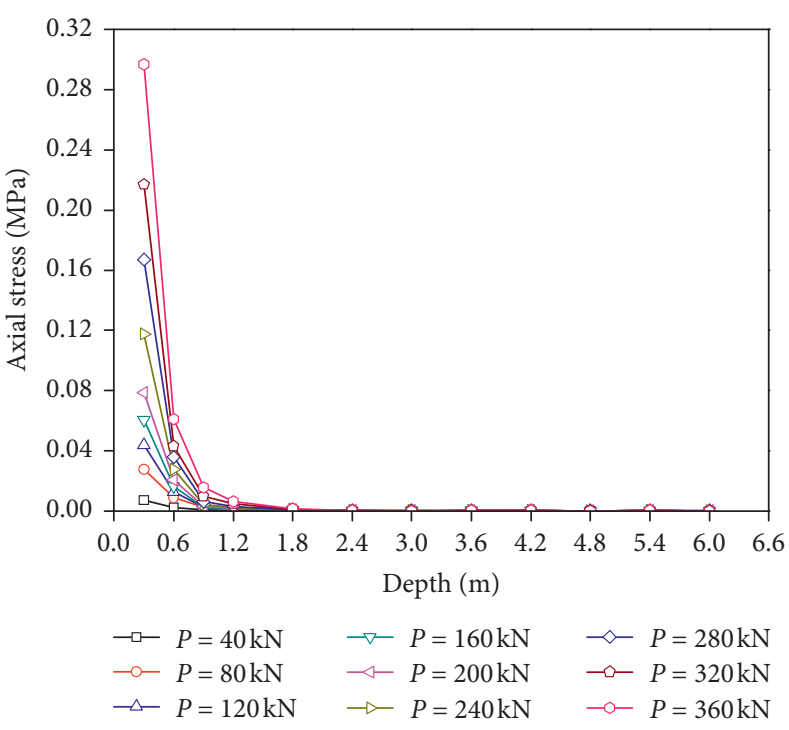

(a)

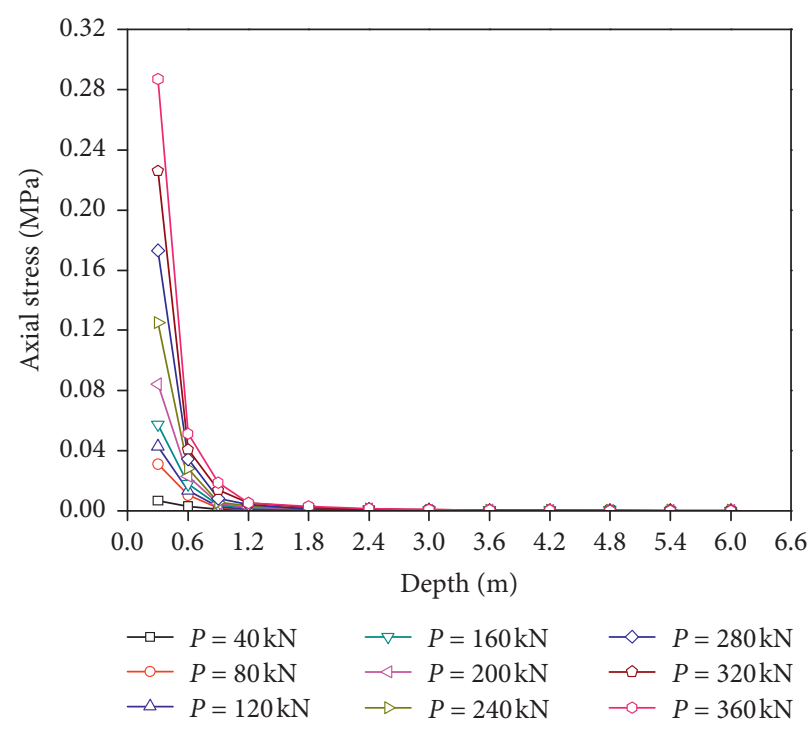

(b)

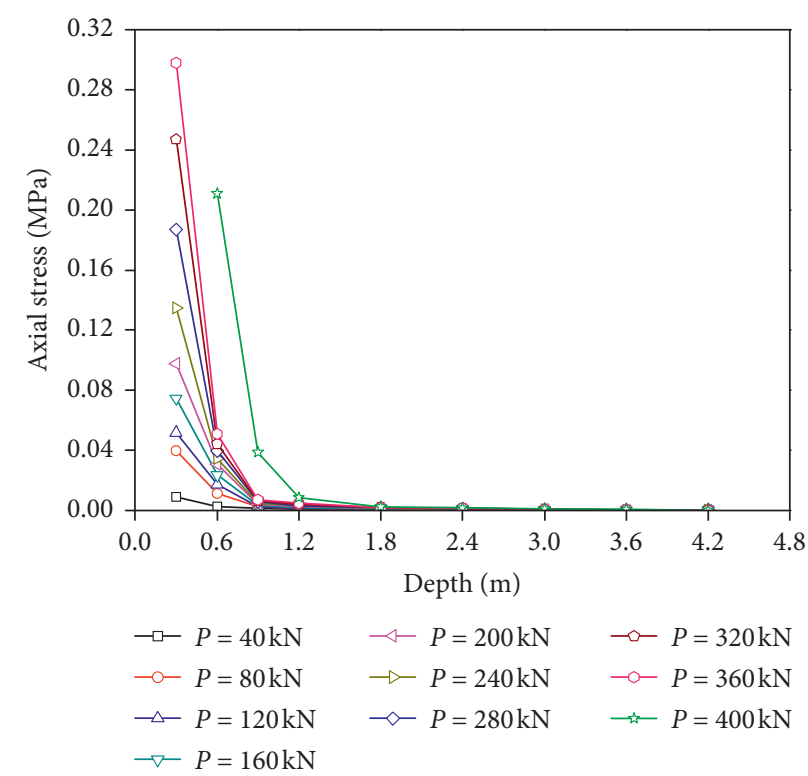

(c)

FIGURE 13: Axial stress of anchor cross-section at different depths: (a) G-28-6.5-1, (b) G-28-6.5-2, and (c) G-28-4.5-1.

improving the rod diameter helps to decrease the displacement difference between the rod and anchorage body. A little displacement difference is significant for preventing the underground water from permeating into the baseplate.

\section{Prediction of Displacement Difference between the Anchor Rod and Anchorage Body}

In this section, a simplified model for the shear stress of the first interface is applied to predict the displacement difference between the anchor rod and the anchorage body.
Assume that the displacements of different positions on the rod cross-section are identical, because the area of the rod cross-section is small. Hence, the displacement of the rod external surface is considered to be the displacement of the anchor rod, whereas the anchorage body has an area of cross-section several times larger than the anchor rod, so the displacement of the head of the anchorage body is considered reducing from the first interface to the second interface linearly, and an average displacement is considered to be the value of the anchorage body. The average displacement of the anchorage body is equal to the displacement of the head of the middle interface. Therefore, the displacement of the head of the middle interface is taken for the 


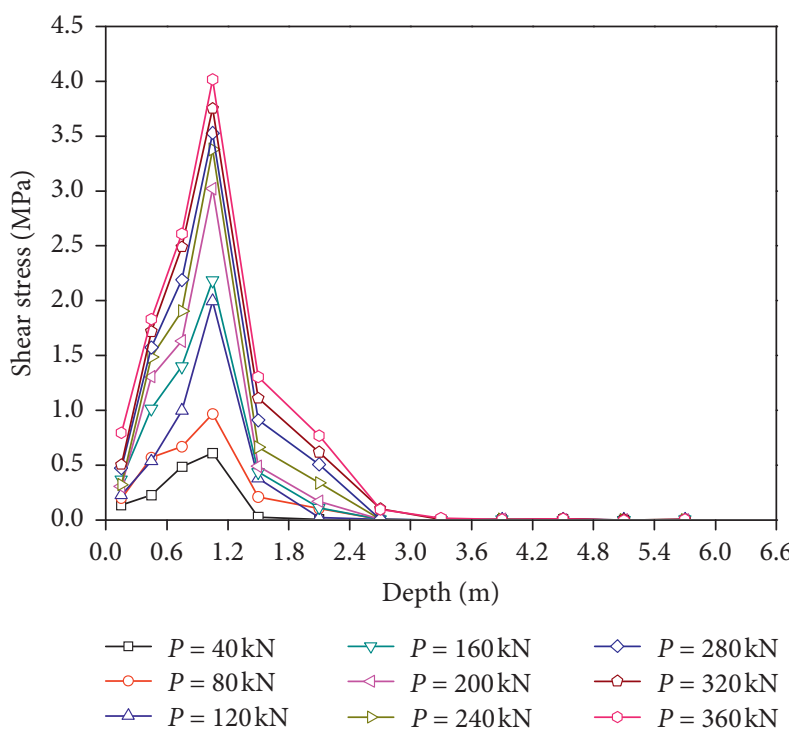

(a)

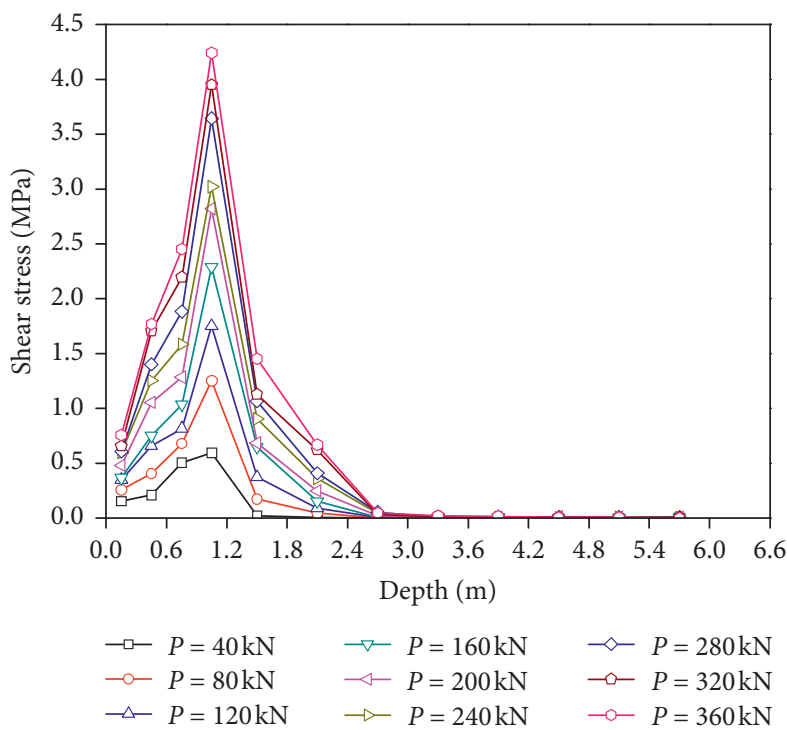

(b)

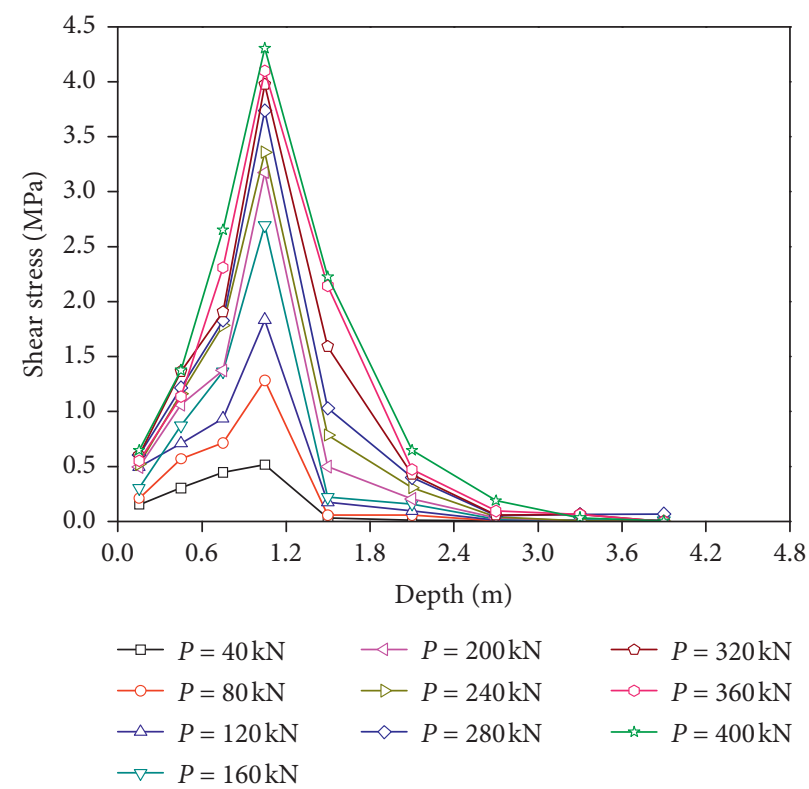

(c)

Figure 14: Shear stress of the first interface at different depths: (a) G-28-6.5-1, (b) G-28-6.5-2, and (c) G-28-4.5-1.

displacement of the anchorage body. The displacements of the anchor rod and anchorage body are shown in Figure 23.

In this paper, the derivation approaches are the same for both rod and anchorage body displacement, so we only introduce the derivation principle of the rod displacement.

Assuming that there is no relative displacement between the rod and the anchorage body, according to Figure 14, the shear stress curve of the first interface is simplified to a triangle as shown in Figure 24. In Figure 24, $\tau_{m}$ is the peak shear stress, $L_{x}$ is the depth of the peak shear stress, $L_{c}$ is the critical anchorage length (i.e., the depth where the shear stress disappears), and $L_{a}$ is the total anchorage length. $L_{x}$ and $L_{c}$ could be acquired by the experimental approach described above.

Usually, the average shear stress, as the rectangle drawn by broken line in Figure 24, is adopted to analyze the holistic level of the anchor shear stress and is expresses as [27]

$$
\tau_{a}=\frac{P}{2 \pi r_{r} L_{c}},
$$

where $\tau_{a}$ is the average shear stress of the first interface, $r_{r}$ is the radius of the anchor rod, and $P$ is the pull-out load.

It is known from (8) that there is a proportional relationship between the value of the load and integral area of 


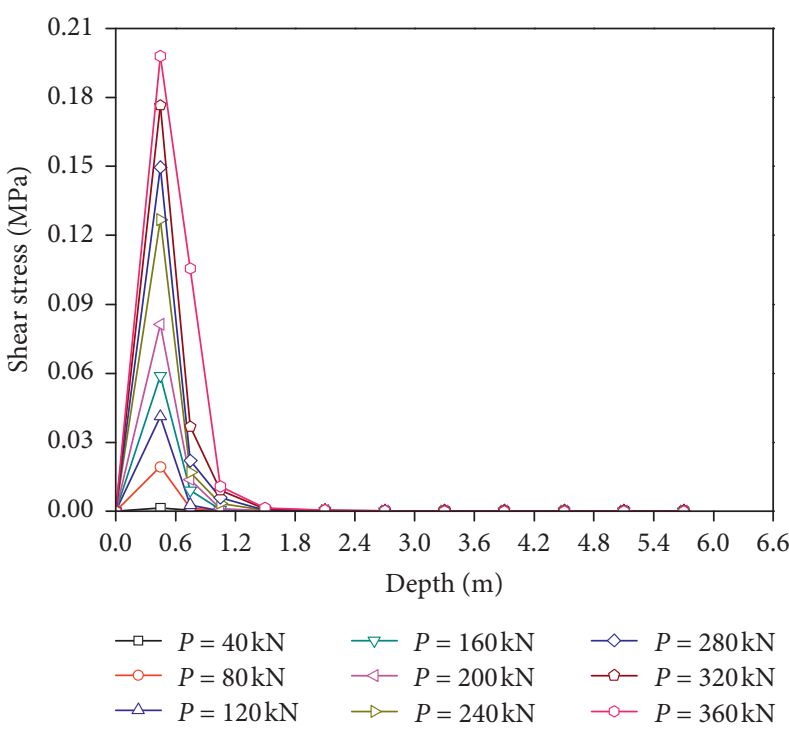

(a)

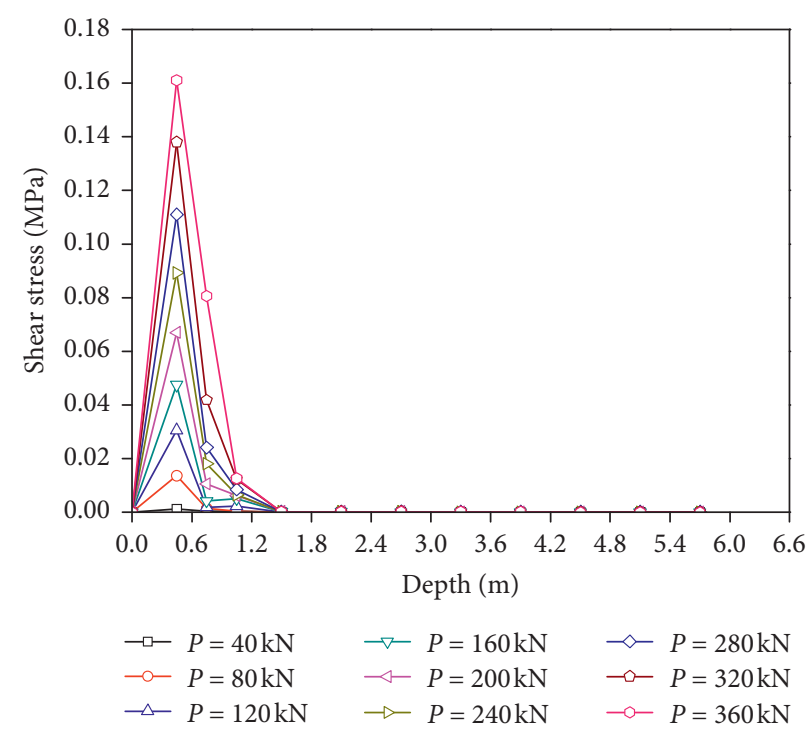

(b)

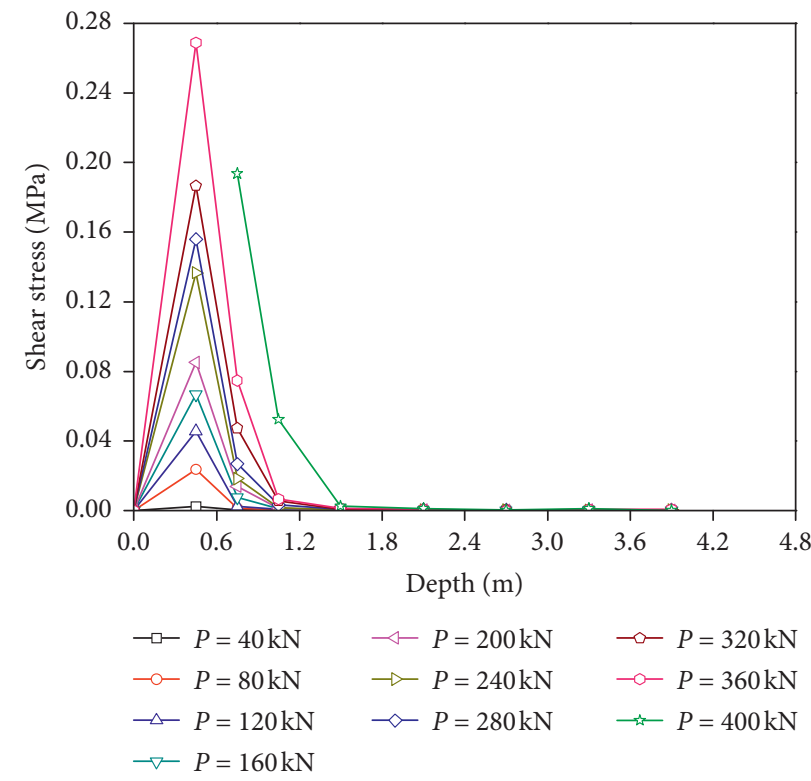

(c)

FIGURE 15: Shear stress of the middle interface at different depths: (a) G-28-6.5-1, (b) G-28-6.5-2, and (c) G-28-4.5-1.

the shear stress, which indicates a constant load corresponding to a constant integral area. The same conclusion of the average shear stress could be made according to (9). Therefore, the area of the triangle (i.e., simplified shear stress) should be equal to the area of the rectangle (i.e., average shear stress) as shown in Figure 24, and the value of $\tau_{m}$ is calculated by

$$
\tau_{m}=2 \tau_{a}=\frac{P}{\pi r_{r} L_{c}} .
$$

Additionally, according to Figure 24, the simplified shear stress is expressed as

$$
\tau(x)=\left\{\begin{array}{l}
\frac{P}{\pi r_{r} L_{c} L_{x}} \cdot x\left(0 \leq x<L_{x}\right), \\
\frac{P}{\pi r_{r} L_{c}} \cdot\left(\frac{L_{c}-x}{L_{c}-L_{x}}\right)\left(L_{x} \leq x<L_{c}\right),
\end{array}\right.
$$

where $\tau(x)$ is the shear stress of the first interface at a depth of $x$.

On the basis of the elastic theory, the distribution function for the axial force of the rod cross-section is expressed as 

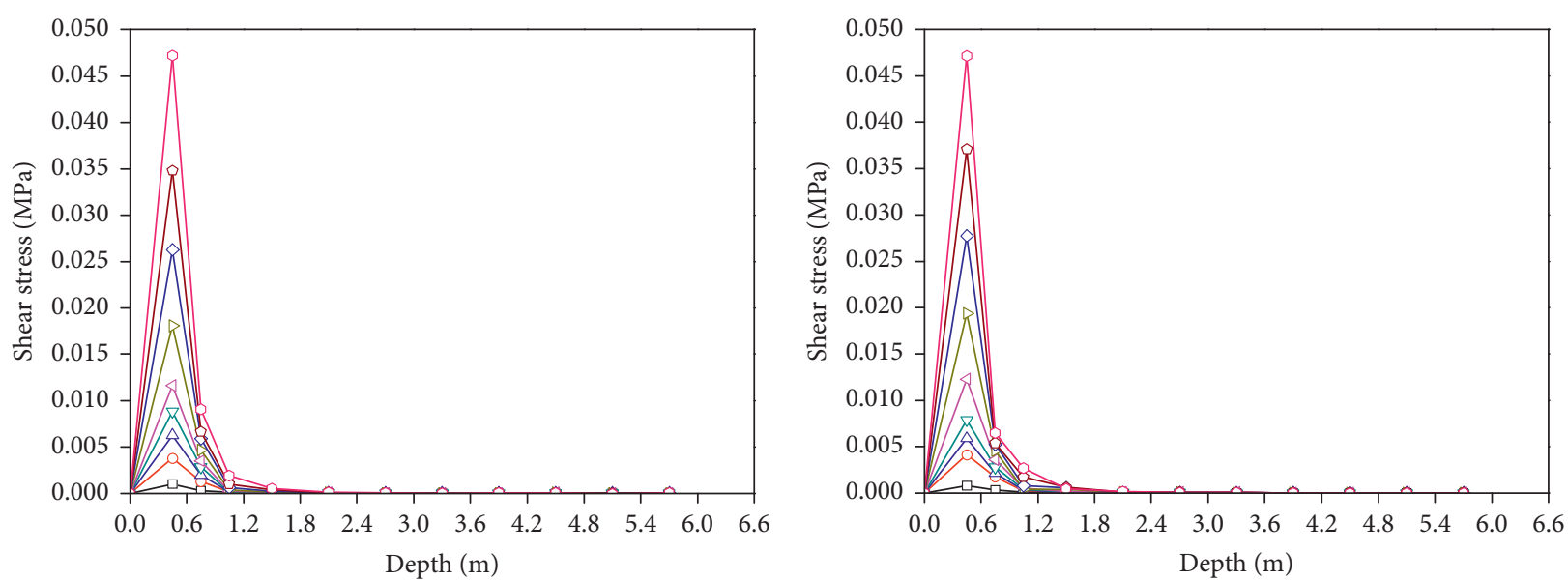

$$
\begin{array}{lll}
\neg-P=40 \mathrm{kN} & \rightarrow-P=160 \mathrm{kN} & \neg P=280 \mathrm{kN} \\
\multimap-P=80 \mathrm{kN} & \multimap-P=200 \mathrm{kN} & \neg P P=320 \mathrm{kN} \\
\neg-P=120 \mathrm{kN} & \rightarrow-P=240 \mathrm{kN} & \multimap P=360 \mathrm{kN}
\end{array}
$$

$$
\begin{array}{lll}
\multimap-P=40 \mathrm{kN} & \rightarrow-P=160 \mathrm{kN} & \neg P=280 \mathrm{kN} \\
\multimap-P=80 \mathrm{kN} & \multimap-P=200 \mathrm{kN} & \multimap P=320 \mathrm{kN} \\
\neg-P=120 \mathrm{kN} & \rightarrow-P=240 \mathrm{kN} & \multimap P P=360 \mathrm{kN}
\end{array}
$$

(a)

(b)

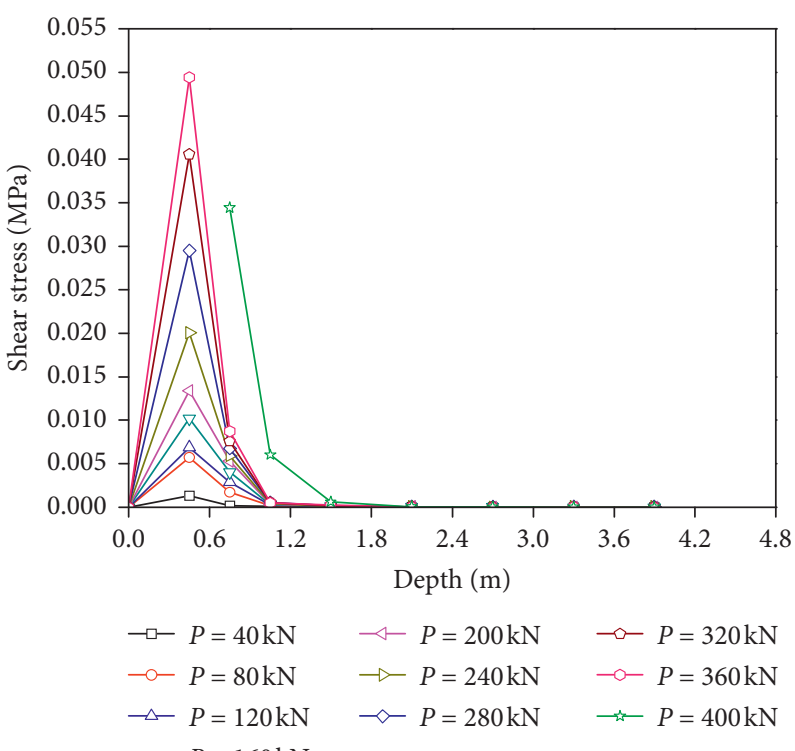

(c)

Figure 16: Shear stress of the second interface at different depths: (a) G-28-6.5-1, (b) G-28-6.5-2, and (c) G-28-4.5-1.

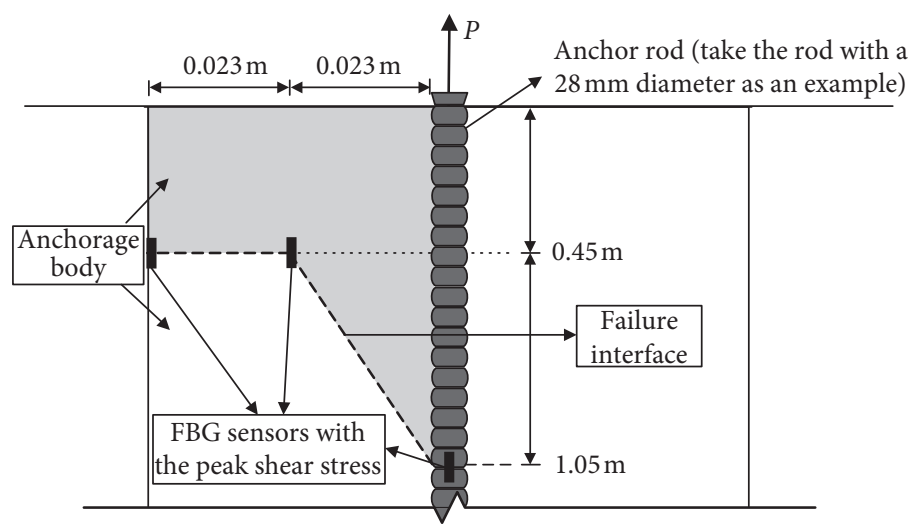

Figure 17: Positions of the FBG sensors with the peak shear stress. 


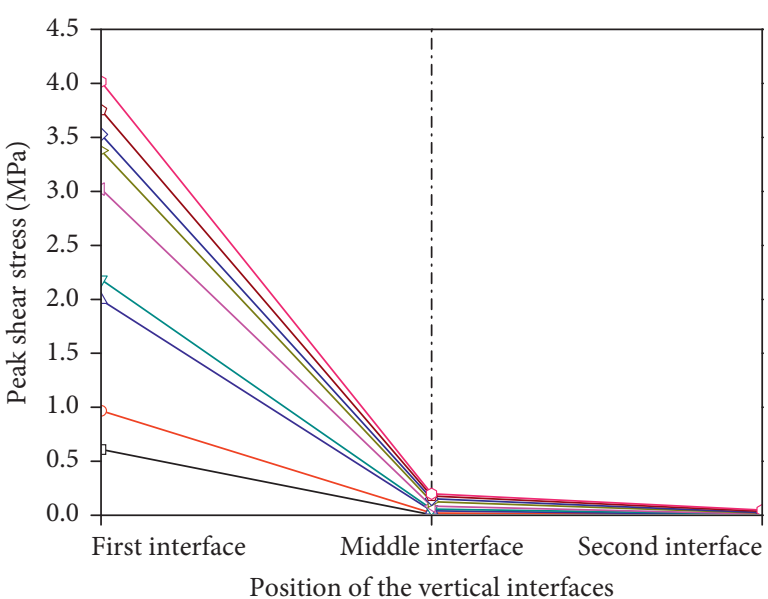

$\begin{array}{lll}\multimap P=40 \mathrm{kN} & \rightarrow P=160 \mathrm{kN} & \multimap-P=280 \mathrm{kN} \\ \multimap-P=80 \mathrm{kN} & \multimap P=200 \mathrm{kN} & \multimap-P=320 \mathrm{kN} \\ \multimap-P=120 \mathrm{kN} & \rightarrow P=240 \mathrm{kN} & \multimap P=360 \mathrm{kN}\end{array}$

(a)

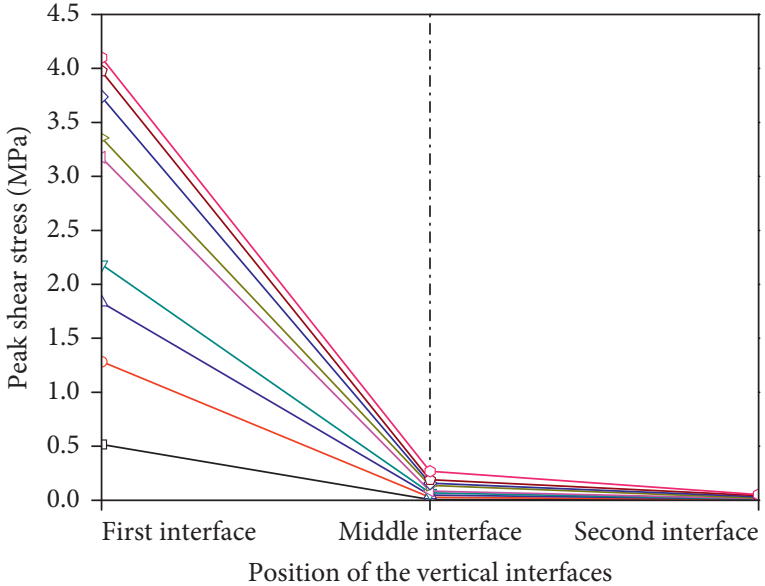

$\neg-P=40 \mathrm{kN} \quad \rightarrow-P=160 \mathrm{kN} \quad \prec P P=280 \mathrm{kN}$

$\multimap P=80 \mathrm{kN} \quad \neg P=200 \mathrm{kN} \quad \multimap P=320 \mathrm{kN}$

$\triangle P=120 \mathrm{kN} \rightarrow P=240 \mathrm{kN} \quad \multimap P=360 \mathrm{kN}$

(b)

FIGURE 18: Variation of the value of peak shear stress in three vertical interfaces: (a) G-28-6.5-1 and (b) G-28-4.5-1.

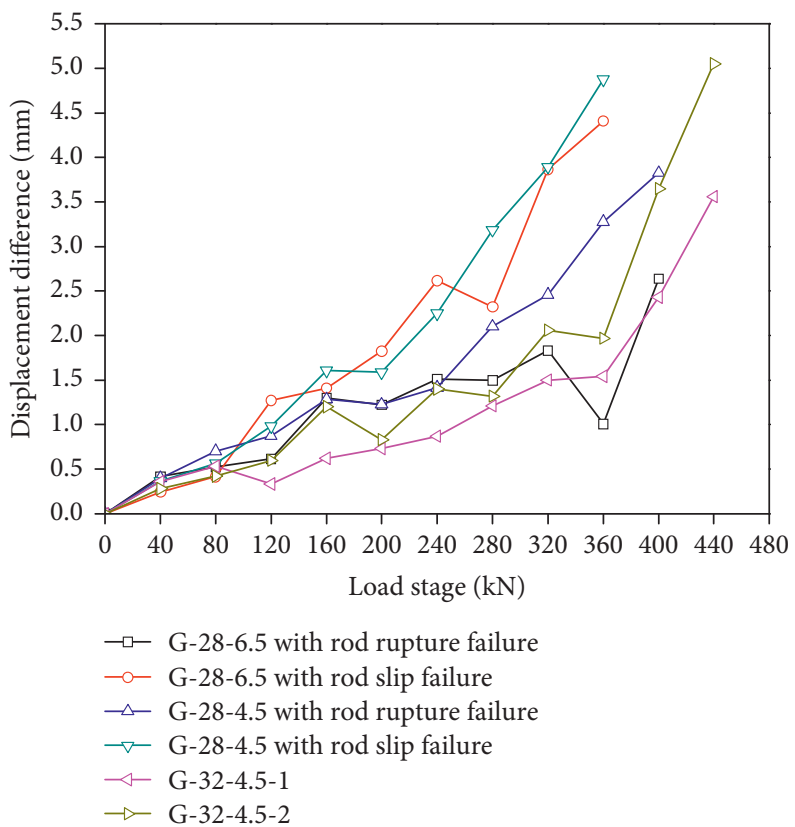

FiguRE 19: Summary of the load-displacement difference curves between the anchor rod and anchorage body.

$$
\begin{aligned}
P(x) & =-2 \pi r_{r} \int_{x}^{L_{c}} \tau(t) \mathrm{d} t \\
& =\left\{\begin{array}{l}
-\frac{P}{L_{c}}\left(L_{c}-\frac{x^{2}}{L_{x}}\right)\left(0 \leq x<L_{x}\right), \\
-\frac{P\left(L_{c}-x\right)^{2}}{L_{c}\left(L_{c}-L_{x}\right)}\left(L_{x} \leq x \leq L_{c}\right),
\end{array}\right.
\end{aligned}
$$

where $P(x)$ is the axial force of the rod cross-section at a depth of $x$.
Then, the elastic deformation of the head of the rod caused by the axial force of the rod cross-section according to Hooke's law will be obtained as follows:

$$
\begin{aligned}
\omega_{r} & =\int_{0}^{L_{c}} \frac{P(x)}{\pi r_{r}^{2} E_{r}} \mathrm{~d} x \\
& =-\frac{P}{3 \pi r_{r}^{2} E_{r}}\left(L_{c}-5 L_{x}+\frac{2 L_{x}^{2}}{L_{c}}\right),
\end{aligned}
$$

where $\omega_{r}$ is the elastic deformation of the head of the rod and $E_{r}$ is the elastic modulus of the rod material. 


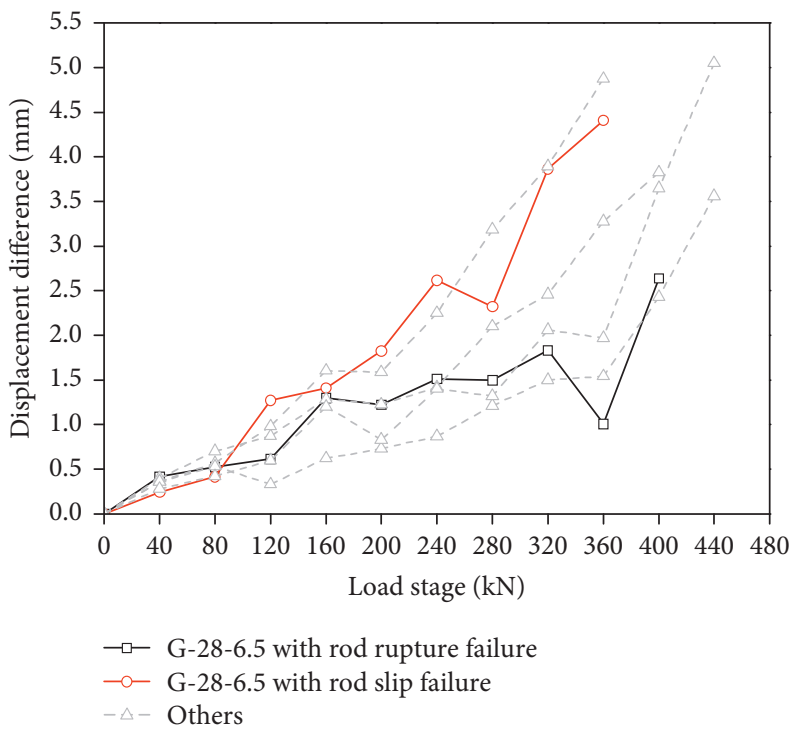

(a)

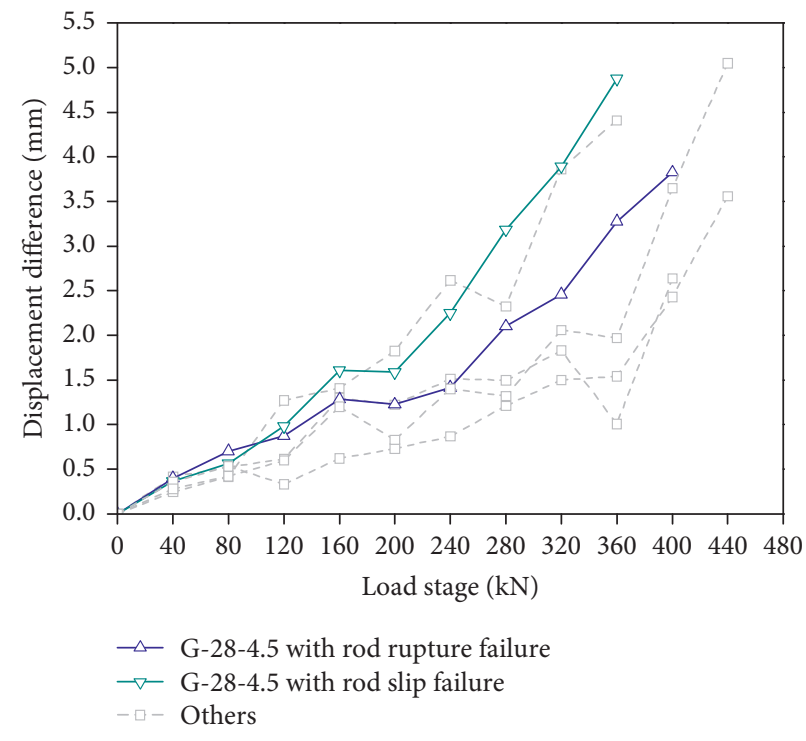

(b)

Figure 20: Load-displacement difference curves of the anchors with different failure modes: (a) G-28-6.5 and (b) G-28-4.5.

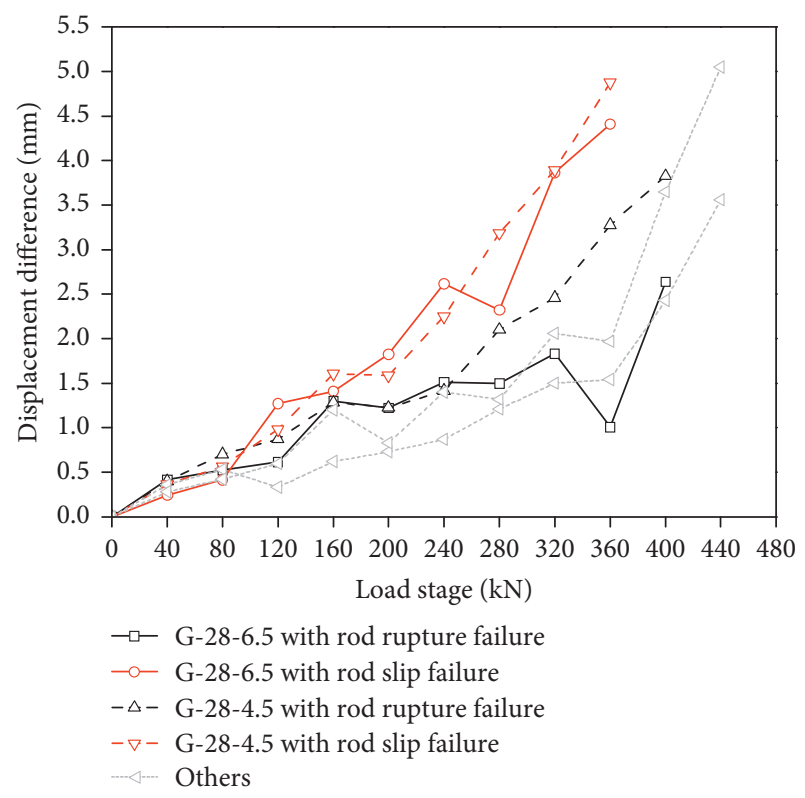

FIGURE 21: Load-displacement difference curves of the anchors with different anchorage lengths.

Based on the same principle, the deformation of the head of the middle interface (i.e., the deformation of the anchorage body) is calculated as

$$
\begin{aligned}
\omega_{b} & =\int_{0}^{L_{c}} \frac{P(x)}{\pi r_{b}^{2} E_{b}} \mathrm{~d} x \\
& =-\frac{P}{3 \pi r_{b}^{2} E_{b}}\left(L_{c}-5 L_{x}+\frac{2 L_{x}^{2}}{L_{c}}\right),
\end{aligned}
$$

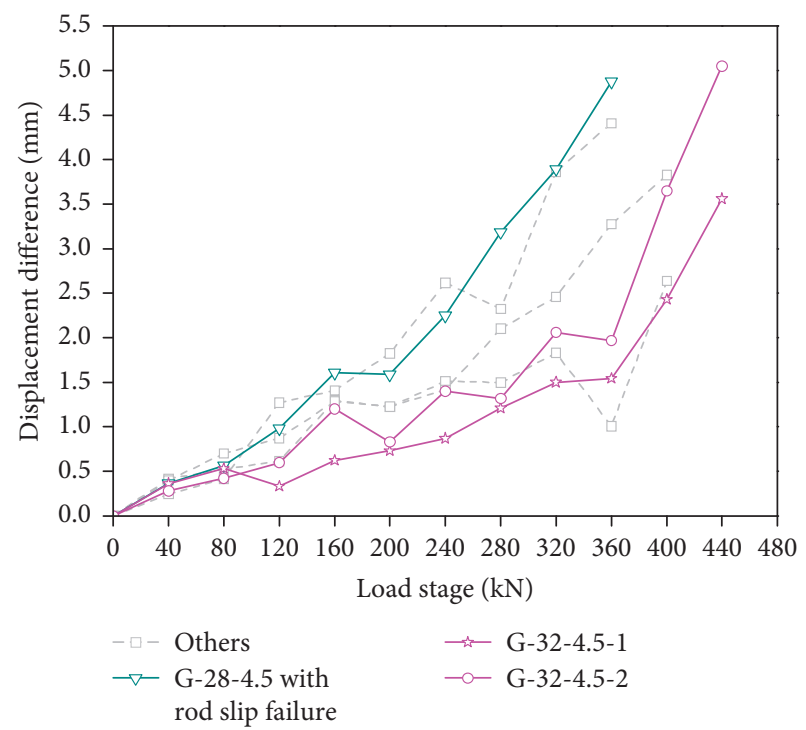

FIGURE 22: Load-displacement difference curves of the anchors with different rod diameters. It should be noticed that the failure modes of the anchors G-32-4.5-1 and G-32-4.5-1 are all rod slip failure.

where $\omega_{b}$ is the deformation of the head of the middle interface, $E_{b}$ is the comprehensive elastic modulus of the middle cross-section (calculated by (4)), and $r_{b}$ is the radius of the middle cross-section.

Finally, the displacement (deformation) difference between the anchor rod and anchorage body is expressed as

$$
\omega=\omega_{r}-\omega_{b}
$$

where $\omega$ is the displacement difference. 


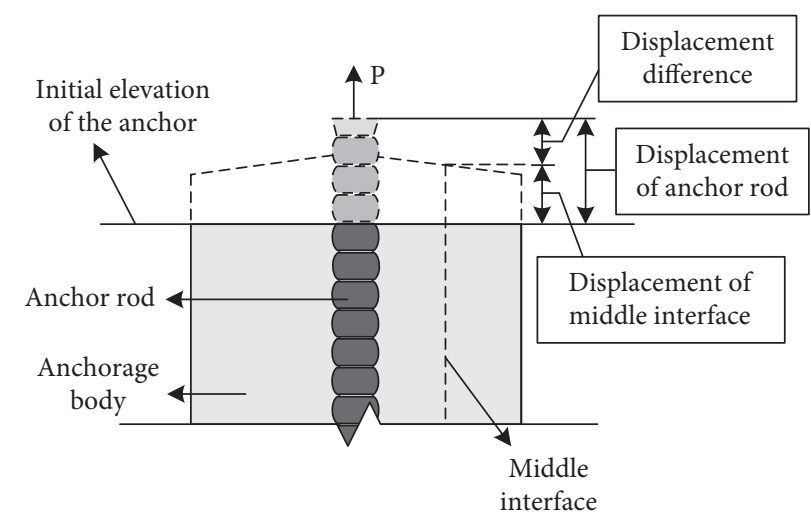

FIgURE 23: Schematic diagram for the displacements of the anchor rod and anchorage body.

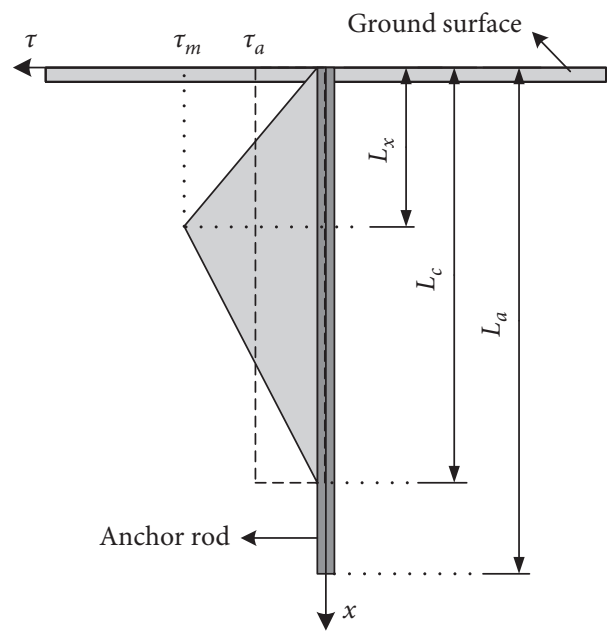

FIgURE 24: Simplified model for the shear stress of the first interface.

Taking anchors G-28-6.5 and G-28-4.5 as examples to make a comparison between the experimental and theoretical results of the rod-anchorage body displacement difference, we found that the calculation parameters of the two types of anchors, as shown in Table 3, are identical. It should be noticed that the comprehensive elastic modulus of the middle cross-section is $24.867 \mathrm{GPa}$ after calculation.

According to equation (15), the comparison results between experimental and theoretical data of the displacement difference are depicted in Figure 25. As shown in Figure 25, in the early stages of the pull-out process (i.e., before $160 \mathrm{kN}$ ), the displacement difference error between the experimental and theoretical data of both types of anchors is not conspicuous. For the anchors with slip failure mode, as the load is increased, there is also an unconspicuous error of the displacement difference error. For the anchors with rupture failure mode, however, the displacement difference error is amplified gradually with the increase of the load. The comparison result indicates the applicability of the elastic approach mentioned above in predicting the rod-anchorage body displacement difference of the anchor with the rod slip failure model.

The accretive displacement difference error of the anchors with rupture failure mode is the result of plastic deformation of these anchors, but the impact mechanism of the plastic deformation is unclear now, which needs future research into this aspect. Furthermore, comparing Figures 25(a) and 25(b), we could make another conclusion that the displacement difference error of the anchors with a rupture failure will be reduced when the anchorage length is closer to the critical anchorage length. 
TABLE 3: Calculation parameters of the anchors G-28-6.5 and G-28-4.5.

\begin{tabular}{lcccc}
\hline Component of the anchor & Elastic modulus $(\mathrm{GPa})$ & Radius $(\mathrm{mm})$ & Critical anchorage length $(\mathrm{mm})$ & Depth of the peak shear stress $(\mathrm{mm})$ \\
\hline Rod & 51 & 14 & 3300 & 1050 \\
Middle interface & 20.492 & 37 & 1500 & 450
\end{tabular}

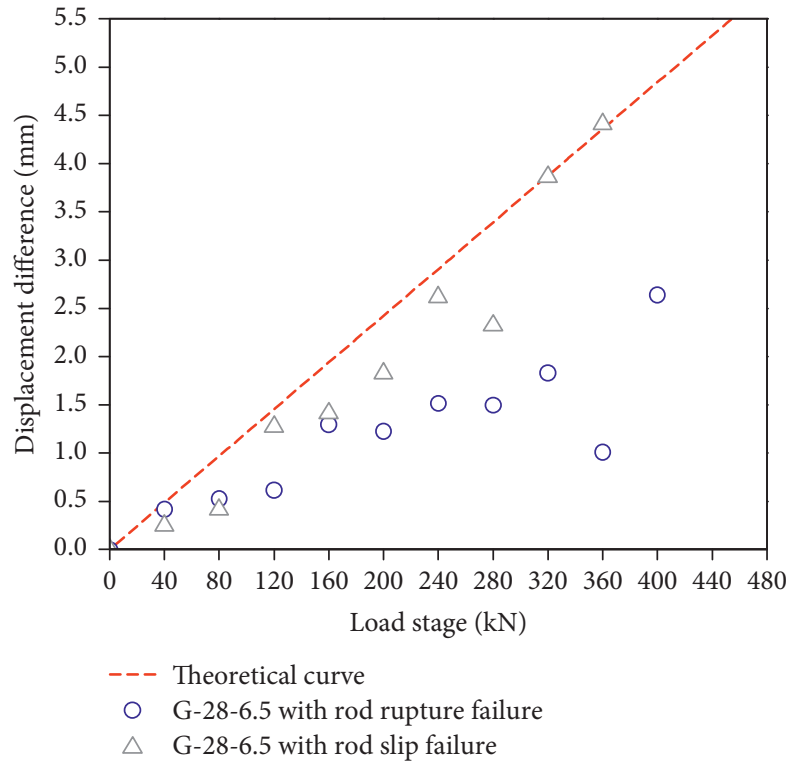

(a)

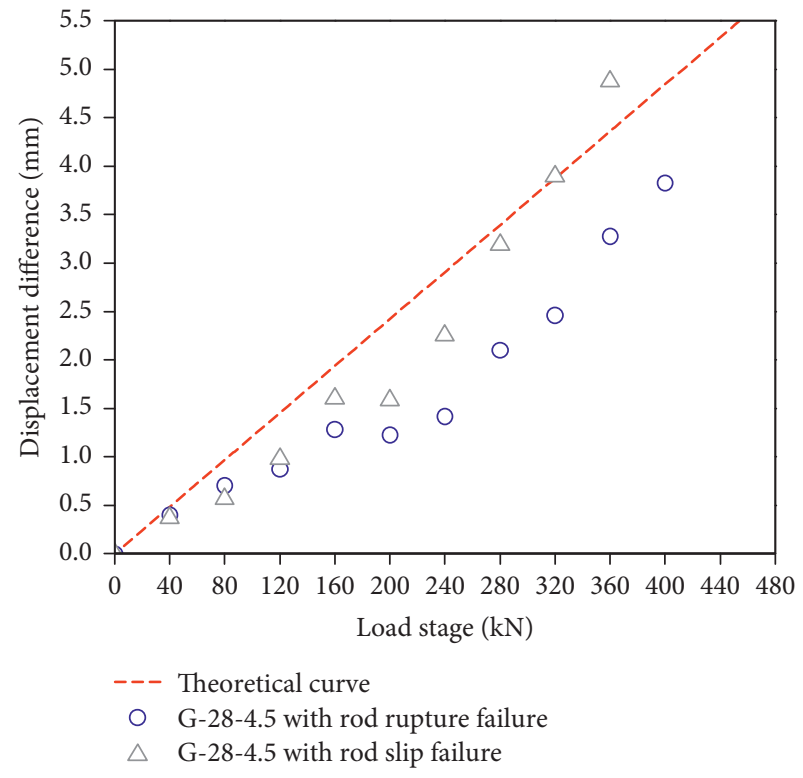

(b)

Figure 25: Comparison of the theoretical curve and experimental results for the load-displacement difference relationship: (a) G-28-6.5 and (b) G-28-4.5.

\section{Conclusions}

Based on the FBG sensor strings technology, pull-out experiments of GFRP antifloating anchors were conducted, and significant data were collected such as failure load, distributions of axial stress and shear stress, and displacements of the rod and anchorage body. On the basis of these data, the following conclusions could be drawn:

(1) Improving the anchorage length continuously is ineffective in promoting the pull-out capacity of the GFRP anchors, but improving the rod diameter is useful for the pull-out capacity improvement.

(2) The distribution curve of the axial stress of the rod cross-section presents a reversed-S shape, which decreases from the head of the anchor hole and disappears near the critical anchorage length. The distribution law for the axial stress curves of other cross-sections is similar to that of the rod crosssection.

(3) The shear stress distribution law of all three monitored vertical interfaces is as follows: increasing first and then decreasing from the position of peak shear stress. The depth of the peak shear stress of different vertical interfaces within the anchorage body moves up from the first interface to the second interface, and the line connecting the peak shear stress points is oblique-upward.

(4) During the later loading stages, the increment speed of the rod-anchorage body displacement difference of the anchors with slip failure is higher than that of the anchors with rupture failure. The rod-anchorage body displacement difference curves of the anchors with an anchorage length that is closer to the critical anchorage length are smoother than those of the anchors with a larger length difference from the critical anchorage length. Moreover, for the anchors with a larger length difference from the critical anchorage length, the curve presents a sudden reduction during one of the later loading stages.

(5) The simplified model for the shear stress is applicable in the prediction of the rod-anchorage body displacement difference of the experimental anchors with a rod slip failure, and the reason of the error when the model is applied for the anchors with rod rupture failure should be further studied.

\section{Data Availability}

The experimental data used to support the findings of this study will be made available upon request to the corresponding author. 


\section{Conflicts of Interest}

The authors declare that there are no conflicts of interest regarding the publication of this paper.

\section{Authors' Contributions}

Xueying Liu mainly engaged in the experiment and research work of soil mechanics and foundation.

\section{Acknowledgments}

The authors would like to acknowledge the support by the National Natural Science Foundation of China (Grant nos. 51708316, 51778312, and 51809146), the China Postdoctoral Science Foundation Funding (Grant no. 2018M632641), the Shandong Key Research and Development Program (Grant nos. 2017GSF16107 and 2018GSF117008), the Shandong Provincial Postdoctoral Innovation Program of China (Grant no. 201903043), the Higher Educational Science and Technology Program of Shandong Province (Grant no. J16LG02), and the Qingdao Postdoctoral Applied Research Program (Grant no. 2018101).

\section{References}

[1] H.-l. Kou, W. Guo, and M.-y. Zhang, "Pullout performance of GFRP anti-floating anchor in weathered soil," Tunnelling and Underground Space Technology, vol. 49, pp. 408-416, 2015.

[2] Z. Achillides and K. Pilakoutas, "Bond behavior of fiber reinforced polymer bars under direct pullout conditions," Journal of Composites for Construction, vol. 8, no. 2, pp. 173-181, 2004.

[3] S. K. Kaushik and S. Islam, "Suitability of sea water for mixing structural concrete exposed to a marine environment," $\mathrm{Ce}$ ment and Concrete Composites, vol. 17, no. 3, pp. 177-185, 1995.

[4] H. Ye, X. Jin, C. Fu, N. Jin, Y. Xu, and T. Huang, "Chloride penetration in concrete exposed to cyclic drying-wetting and carbonation," Construction and Building Materials, vol. 112, pp. 457-463, 2016.

[5] T. M. Pham and H. Hao, "Review of concrete structures strengthened with FRP against impact loading," Structures, vol. 7, pp. 59-70, 2016.

[6] X.-L. Zhao and L. Zhang, "State-of-the-art review on FRP strengthened steel structures," Engineering Structures, vol. 29, no. 8, pp. 1808-1823, 2007.

[7] D. Lau, Q. Qiu, A. Zhou, and C. L. Chow, "Long term performance and fire safety aspect of FRP composites used in building structures," Construction and Building Materials, vol. 126, pp. 573-585, 2016.

[8] T. Ozbakkaloglu and M. Saatcioglu, "Tensile behavior of FRP anchors in concrete," Journal of Composites for Construction, vol. 13, no. 2, pp. 82-92, 2009

[9] Z. He and G.-W. Tian, "Probabilistic evaluation of the design development length of a GFRP rod pull-out from concrete," Engineering Structures, vol. 33, no. 10, pp. 2943-2952, 2011.

[10] B. Benmokrane, M. Robert, H. M. Mohamed, A. H. Ali, and P. Cousin, "Durability assessment of glass FRP solid and hollow bars (rock bolts) for application in ground control of Jurong rock caverns in Singapore," Journal of Composites for Construction, vol. 21, no. 3, Article ID 06016002, 2017.
[11] L. Vint, "Investigation of bond properties of glass fibre reinforced polymer (GFRP) bars in concrete under direct tension," School of Graduate Studies, University of Toronto, Toronto, Canada, 2012.

[12] K. M. A. Hossain, "Bond strength of GFRP bars embedded in engineered cementitious composite using RILEM beam testing," International Journal of Concrete Structures and Materials, vol. 12, no. 1, p. 6, 2018.

[13] G. B. Maranan, A. C. Manalo, W. Karunasena, and B. Benmokrane, "Pullout behaviour of GFRP bars with anchor head in geopolymer concrete," Composite Structures, vol. 132, pp. 1113-1121, 2015.

[14] M. Y. Zhang, Z. Kuang, X. Y. Bai, and X. Y. Chen, "Pullout behavior of GFRP anti-floating anchor based on the FBG sensor technology," Mathematical Problems in Engineering, vol. 2018, Article ID 6424791, 10 pages, 2018.

[15] R. M. Guedes, C. M. L. Tavares, and A. J. M. Ferreira, "Experimental and theoretical study of the creep behavior of GFRP-reinforced polymer concrete," Composites Science and Technology, vol. 64, no. 9, pp. 1251-1259, 2004.

[16] N.-K. Kim, "Performance of tension and compression anchors in weathered soil," Journal of Geotechnical and Geoenvironmental Engineering, vol. 129, no. 12, pp. 1138-1150, 2003.

[17] B. Zhang, B. Benmokrane, A. Chennouf, P. Mukhopadhyaya, and A. El-Safty, "Tensile behavior of FRP tendons for prestressed ground anchors," Journal of Composites for Construction, vol. 5, no. 2, pp. 85-93, 2001.

[18] S. Yang, Z. Wu, X. Hu, and J. Zheng, "Theoretical analysis on pullout of anchor from anchor-mortar-concrete anchorage system," Engineering Fracture Mechanics, vol. 75, no. 5, pp. 961-985, 2008.

[19] Q. Jin, G. Wang, T. Liang, and P. Chen, "Bond-slip behavior between GFRP bars and mortar based on pull-out tests," Polymer Composites, vol. 40, no. 7, pp. 2840-2849, 2018.

[20] J.-Y. Lee, T.-Y. Kim, T.-J. Kim et al., "Interfacial bond strength of glass fiber reinforced polymer bars in high-strength concrete," Composites Part B: Engineering, vol. 39, no. 2, pp. 258-270, 2008.

[21] H.-N. Li, D.-S. Li, and G.-B. Song, "Recent applications of fiber optic sensors to health monitoring in civil engineering," Engineering Structures, vol. 26, no. 11, pp. 1647-1657, 2004.

[22] B. Torres, I. Payá-Zaforteza, P. A. Calderón, and J. M. Adam, "Analysis of the strain transfer in a new FBG sensor for structural health monitoring," Engineering Structures, vol. 33, no. 2, pp. 539-548, 2011.

[23] H. Ostermayer and F. Scheele, "Research on ground anchors in non-cohesive soils," Revue Française de Géotechnique, vol. 3, no. 3, pp. 92-97, 1978.

[24] Q. Zhao and J. H. Liu, "Experimental study and theoretical analysis on the bond behavior of cement grouted GFRP bolts," in Proceedings of the Slope Stability and Earth Retaining Walls, pp. 41-47, Hunan, China, May 2011.

[25] A. Ghaly and A. Hanna, "Model investigation of the performance of single anchors and groups of anchors," Canadian Geotechnical Journal, vol. 31, no. 2, pp. 273-284, 1994.

[26] G. Liu and C. Sun, "Analyses of the elastic modulus values of masonry," Journal of Hunan University, vol. 35, no. 4, pp. 29-32, 2008.

[27] J.-P. Won, C.-G. Park, H.-H. Kim, S.-W. Lee, and C.-I. Jang, "Effect of fibers on the bonds between FRP reinforcing bars and high-strength concrete," Composites Part B: Engineering, vol. 39, no. 5, pp. 747-755, 2008. 